\title{
IMPACTO EDUCACIONAL \\ DO MECANISMO DE REPARTIÇÃO \\ DA QUOTA-PARTE DO ICMS \\ COM OS MUNICÍPIOS DO \\ ESTADO DO CEARÁ*
}

\section{Guilherme Irffi'}

\author{
Armando Simões" \\ Diego Carneiro"II \\ Cristiano da Silvalv
}

http://dx.doi.org/10.24109/27635139.ceppe.v3i4.4891

\section{RESUMO}

A agenda política nacional tem ampliado a atenção sobre a importância de mecanismos de incentivo e/ou de compensação para a promoção de melhorias no desempenho educacional básico. Nesse sentido, a regra de distribuição da quota-parte do ICMS $^{1}$ no Ceará é considerada um importante benchmark em termos estratégicos. Na medida em que a distribuição de recursos no estado passou a ser vinculada à qualidade educacional dos municípios, o desenho do mecanismo adotado possui capacidade de alinhar os objetivos

\footnotetext{
* Os autores agradecem ao auxílio de Camila Guedes Correa e Brysa Fernandes na compilação das leis de incentivo à educação via distribuição de quota parte do ICMS, ao Francisco Antônio de Araújo pelos comentários no texto das evidências empíricas da intervenção via quota-parte do ICMS-educacional. Ressaltando que erros e omissão são de nossa responsabilidade.

I Doutor em Economia pelo Programa de Pós-Graduação em Economia da Universidade Federal do Ceará (Caen/UFC). Professor do Departamento de Economia Aplicada e do Programa de Pós-Graduação em Economia, Caen-UFC.

II PhD em Educação pela Universidade de Sussex, no Reino Unido. É da carreira de Especialista em Políticas Públicas e Gestão Governamental em exercício no Instituto Nacional de Estudos e Pesquisas Educacionais Anísio Teixeira (Inep) na Diretoria de Estudos Educacionais (Dired).

III Doutor em Economia pelo Programa de Pós-Graduação em Economia, Caen/UFC. Economista na UFC.

Iv Professor do Departamento de Economia e do Programa de Pós-Graduação em Economia, Mestrado em Economia, Universidade do Estado do Rio Grande do Norte (UERN).

${ }^{1}$ ICMS é acrograma de Imposto sobre Operações relativas à Circulação de Mercadorias e Prestação de Serviços de Transporte Interestadual e Intermunicipal e de Comunicação.
} 
dos gestores municipais em relação às preferências do estado, reduzindo o problema do tipo Agente-Principal. Diante disso, este artigo faz uma contextualização geral das leis vigentes em outros estados para a repartição da quota-parte municipal, discutindo as principais semelhanças e diferenças referentes à regra de distribuição cearense. É realizado também um estudo quantitativo a fim de subsidiar evidências sobre o diferencial de impacto da lei da quota-parte cearense quanto às demais regras estaduais, considerando medidas em termos de desempenho e de fluxo educacional. A regra de distribuição do Ceará exerce um substancial efeito positivo sobre os indicadores de desempenho educacional, entretanto, os resultados apontam também aumento da taxa de abandono em relação aos municípios dos grupos de comparação.

Palavras-chave: educação básica; ICMS; incentivos fiscais; transferências intergovernamentais.

\section{INTRODUÇÃO}

A agenda política nacional tem ampliado a atenção sobre a importância de mecanismos de incentivo e/ou de compensação para a promoção de melhorias no desempenho do ensino básico. Nesse sentido, a regra de distribuição da quota-parte do ICMS no Ceará é considerada um importante benchmark em termos estratégicos e em função dos resultados educacionais apresentados pelo estado. Segundo Carneiro (2018), uma explicação para os resultados observados no ensino básico no Ceará é derivada do alinhamento dos incentivos entre todos os atores no processo educacional. $\mathrm{O}$ estado construiu uma rede de incentivos que premia o resultado, abrangendo desde o gestor municipal até o aluno, passando por diretores e professores, de modo que todos auferem ganhos financeiros e reconhecimento em função do resultado alcançado. Com isso, foi estabelecido um ciclo virtuoso de competição por recursos e reconhecimento.

Todavia, é importante destacar que as mudanças educacionais no Ceará datam da década de 1990, com a criação do Sistema Permanente de Avaliação da Educação Básica do Ceará (Spaece) e com a distribuição de 12,5\% dos recursos da quota-parte do ICMS para os municípios com base no percentual das receitas de impostos e das transferências constitucionais aplicado em educação em cada município (Lei n ${ }^{\circ}$ 12.612/1996). O aumento de recursos para a educação básica, tanto proveniente da quota-parte do ICMS quanto do Fundo de Manutenção e Desenvolvimento do Ensino Fundamental e de Valorização do Magistério (Fundef), propiciou um acréscimo significativo no número e na taxa de matrículas desse nível de ensino. No entanto, ao incluir e assegurar o acesso para as crianças na educação básica, os resultados em termos de proficiência no Ceará e no Brasil apresentaram uma queda no começo dos anos 2000. 
A melhoria quanto à proficiência no Ceará é mais recente e vem sendo associada à alteração no mecanismo de incentivo para distribuir recursos do ICMS no estado, que passou a ser vinculado à qualidade educacional dos municípios a partir da Lei $\mathrm{n}^{0} 14.023 / 2007$. Esse novo desenho de mecanismo, alinhando os objetivos dos gestores municipais em relação às preferências do estado, colaborou para mitigar o problema do tipo Agente-Principal.

Em razão disso, este texto contribui com a literatura que estuda o impacto das mudanças na lei estadual do ICMS sobre os resultados da educação. A seção seguinte apresenta a teoria da intervenção por meio da função de produção educacional e de como o mecanismo do "ICMS-educacional" pode contribuir para melhores resultados na educação. A terceira seção descreve e analisa as alterações nas regras de distribuição da quota-parte do ICMS no Ceará desde a década de 1990. A quarta seção apresenta as leis vigentes que condicionam a distribuição de recursos a indicadores educacionais em outros estados, com base em insumos, produtos ou resultados. A quinta seção exibe uma revisão da literatura empírica sobre os resultados da distribuição de quota-parte do ICMS em indicadores educacionais. A sexta seção descreve a evolução dos indicadores educacionais no Ceará. A partir da revisão da literatura empírica, a sétima seção expõe uma estratégia de identificação para analisar o impacto e a efetividade da lei cearense, tanto em termos de proficiência do $5^{\circ}$ ano do ensino fundamental (EF) quanto do Índice de Desenvolvimento da Educação Básica (Ideb) e das taxas de rendimentos dos anos iniciais. Na última seção, são apresentadas as considerações finais.

\section{A TEORIA DA INTERVENÇÃO DO “ICMS-EDUCACIONAL"}

Mankiw (2001) elenca o que considera os dez princípios de Economia, dos quais quatro remetem ao modo como os agentes econômicos tomam suas decisões. O autor introduz noções básicas de trade off e custo de oportunidade e, em seu quarto enunciado, traz o conceito de que "pessoas respondem a incentivos". Isso é uma consequência do comportamento otimizado que fundamenta a teoria microeconômica e está intimamente ligado ao desenho de distribuição de quota-parte municipal do ICMS com base em resultados educacionais.

Para compreender como essas ideias se concatenam, deve-se ter em mente que o aprendizado é o resultado da interação de diversos agentes que atuam em diferentes dimensões do processo educacional. Nesse sentido, Glewwe e Kremer (2006) propõem que é possível entender a acumulação de conhecimento por meio da Função de Produção do Aprendizado (FPE), cujos insumos são as características dos atores e as instituições envolvidas nesse processo, conforme a seguinte especificação:

$$
A=a(S, Q, C, H, I)
$$


Em que $A$ representa o aprendizado, $S$ são os anos de estudo, $Q$ é um vetor de características da escola e dos professores, $C$ é um vetor de características dos alunos, $H$ é um vetor de características das famílias e $I$ é um vetor do investimento realizado pelos pais. Este último insumo pode ser estendido para contemplar a totalidade dos recursos educacionais à disposição dos estudantes, o que incluiria também o investimento realizado pela rede de ensino pública municipal, estadual ou federal.

O que distingue fundamentalmente a aprendizagem de um processo produtivo, no sentido clássico, é que a combinação dos insumos depende da cooperação de agentes que não necessariamente possuem os mesmos objetivos. O gestor público, por exemplo, pode visar maximizar seu capital político, privilegiando políticas nesse sentido; os pais, acreditando que a educação é um investimento, buscam aumentar os ganhos financeiros futuros dos filhos; os professores e diretores possuem tanto interesse em ganhos financeiros pessoais quanto de status e altruísmo para aprimorar as aulas e ter melhores resultados; e, por fim, os próprios alunos podem sofrer do viés do presente, que os leva a subestimar os benefícios futuros advindos da educação. A consequência desse desalinhamento é a existência de ineficiências, ou seja, a produção pode se dar em um ponto subótimo, abaixo de sua capacidade efetiva.

Nos termos empregados por Mankiw (2001), a princípio, existe um fraco incentivo para os agentes cooperarem em busca de um ganho de aprendizado, visto que isso implica custos relacionados a esforço, os quais podem não contribuir para o atingimento dos objetivos individuais. Dessa forma, considerando essa pluralidade de interesses, é possível elaborar um mecanismo de compensação, em geral financeira, que permita alinhar os objetivos de todos os agentes, elevando a eficácia do processo educacional.

Para tanto, é preciso identificar como cada um dos agentes contribui para o aprendizado por meio de um sistema de accountability e, então, premiar o esforço. Está implícita aqui a premissa de que este aumenta as chances de obter melhores resultados, porém, a um custo de desutilidade dos agentes ${ }^{2}$. Dessa forma, professores, ao despenderem mais tempo na preparação de aulas ou se aperfeiçoando, tenderiam a contribuir positivamente para o aprendizado dos alunos, mas ao custo, por exemplo, de seu tempo de lazer ou de um outro vínculo empregatício.

Os alunos são um caso particular nessa dinâmica, por serem ao mesmo tempo agentes e pretensos beneficiários (clientes) da política educacional. Em uma abordagem racional, eles analisam o custo e o benefício esperado de obter educação e decidem quanto esforço alocar para ter melhor resultado educacional, medido, por exemplo, em exames padronizados. Assim, deve-se considerar o benefício esperado pelo estudante (denominado como montante), que depende das condições do mercado de trabalho no futuro (prêmio de habilidade) e do risco, uma vez que existe uma probabilidade, dado o esforço, de o aluno obter o benefício.

\footnotetext{
2 Quanto maior o nível de esforço, maior o custo do trabalho, logo, maior a desutilidade. Ou seja, esta pode ser entendida como a renúncia à utilidade.
} 
Cabe observar que, visto que os estudantes são propensos a possuir elevadas taxas de desconto intertemporal, a redução de custo presente tende a ser muito mais eficaz do que melhoras nas perspectivas futuras. Em casos extremos, alterações nesses parâmetros podem levar ao abandono e à evasão, o que eleva a importância dos demais atores em facilitar o processo de aprendizagem.

A partir das características dos agentes, é possível desenhar um "contrato" em que eles são premiados conforme sua contribuição para o resultado educacional. As práticas mais comuns são a distribuição de bônus financeiros para professores e diretores ou as premiações às escolas ou à comunidade (municípios). A aferição dos resultados se dá mediante indicadores como gasto por aluno, taxas de atendimento e aprovação ou desempenho dos estudantes em avaliações externas.

Outra modalidade comumente empregada é a premiação direta aos estudantes, o que possui a vantagem de reduzir marginalmente o custo líquido presente desses alunos. Contudo, essa modalidade pode conter uma assimetria de incentivos perversa, uma vez que os discentes mais habilidosos possuem menor custo em se educar, logo aceitam incentivos menores. Assim, para atingir o máximo de alunos, o prêmio deve ser grande o suficiente, o que, no limite, pode tornar o programa inviável financeiramente, devendo sempre ser considerado o custo-benefício da política. Por outro lado, é possível contrabalancear o custo do prêmio reduzindo o esforço necessário para obtê-lo. Alguns exemplos de benefícios são: i) bonificar o aluno/escola com melhor nota (prêmio alto, chance baixa); ii) bonificar todos os que atingirem determinada nota (prêmio médio, chance mediana); iii) bonificar todos os alunos/escolas como proporção de sua nota (prêmio pequeno, chance alta).

Assim, dada a diversidade de opções de esquemas de compensação e incentivo, faz-se necessário definir as diretrizes de um contrato efetivo no contexto do rateio do ICMS para a educação. Carneiro e Irffi (2018b) analisam essa questão a partir da ótica de um problema de risco moral por meio do arcabouço teórico do modelo de Agente-Principal, aplicado ao contexto microeconômico, para modelar a relação entre estados e municípios sobre a distribuição de quota-parte do ICMS com base em resultados educacionais. Segundo os autores, o contrato será tão mais efetivo: i) quanto mais claras forem as regras e objetivos, de modo que o agente consiga calcular adequadamente suas chances e nível de esforço; ii) ao se basear em um indicador que de fato possa ser alterado pela ação do agente; e iii) cujo prêmio seja suficiente para compensar o esforço despendido.

\section{DESCRIÇÃO DO MODELO DE REPARTIÇÃO DA QUOTA- PARTE MUNICIPAL DO ICMS NO ESTADO DO CEARÁ}

A Constituição Federal de 1988, art. 158, inciso IV, dispõe que 25\% do produto da arrecadação do ICMS pertence aos municípios. Ou seja, dessa arrecadação, 75\% pertencem ao estado e ao Distrito Federal e, por isso, são destinados ao Tesouro Estadual (Distrital); enquanto o restante (25\%) deve ser devolvido aos municípios. 
Do montante que compete aos municípios, $18,75 \%$ (ou $75 \%$ da quota) devem ser distribuídos conforme o Valor Adicionado Fiscal (VAF) desses entes, enquanto $6,25 \%$ (ou os $25 \%$ restantes) cabem ao estado e ao Distrito Federal legislarem sobre a forma de distribuição. A Figura 1 representa a distribuição dos recursos arrecadados de ICMS conforme a Constituição Federal de 1988.

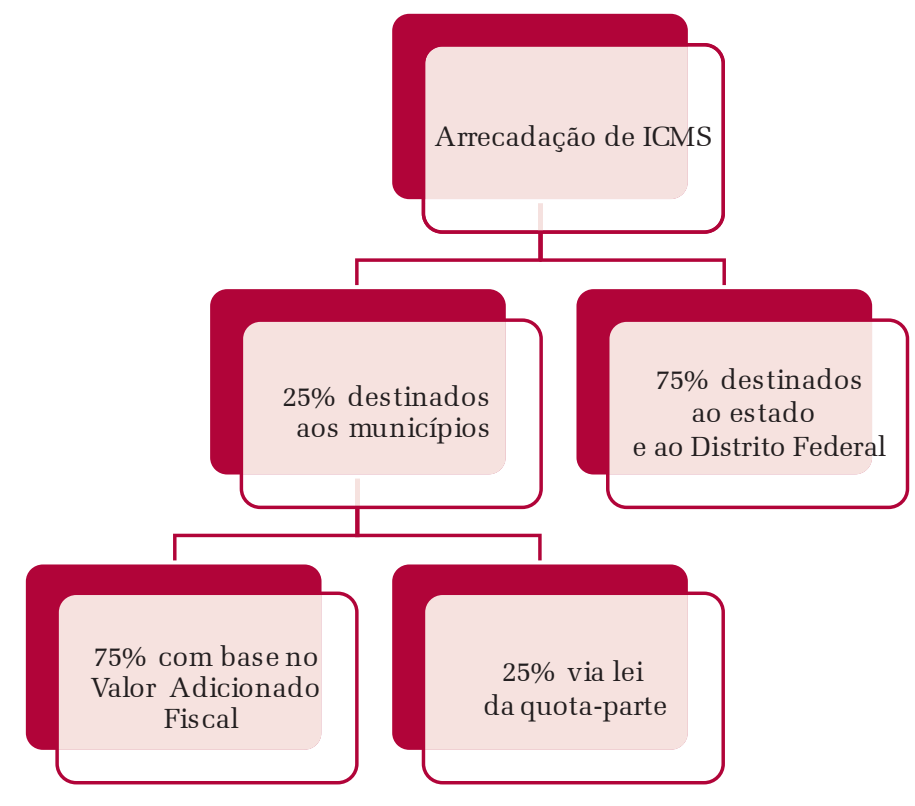

FIGURA 1

A DISTRIBUIÇÃO DO ICMS ENTRE ESTADO, DISTRITO FEDERAL E MUNICÍPIOS, SEGUNDO A CONSTITUIÇÃO FEDERAL DE 1988

Fonte: Elaboração própria.

Diante disso, o governo do Ceará estabeleceu por meio da Lei $\mathrm{n}^{0} 12.172$, de 24 de setembro de 1993, os critérios de distribuição da quota-parte municipal, ou seja, o rateio de $25 \%$ da arrecadação de ICMS que pertence aos municípios. Essa lei determinou que, dos 25\%, 15\% sejam distribuídos com base proporcional à população e os demais, $10 \%$, divididos considerando o critério igualitário.

Por meio da Lei $\mathrm{n}^{0} 12.612$, de 7 de agosto de 1996, o governo do estado alterou os parâmetros da distribuição de recursos da quota-parte do ICMS. Como se observa na Figura 2, os recursos da quota-parte municipal passaram a ser distribuídos conforme os seguintes critérios: 5\% proporcional à população, 7,5\% de parte igualitária e 12,5\% proporcional ao gasto educacional. 


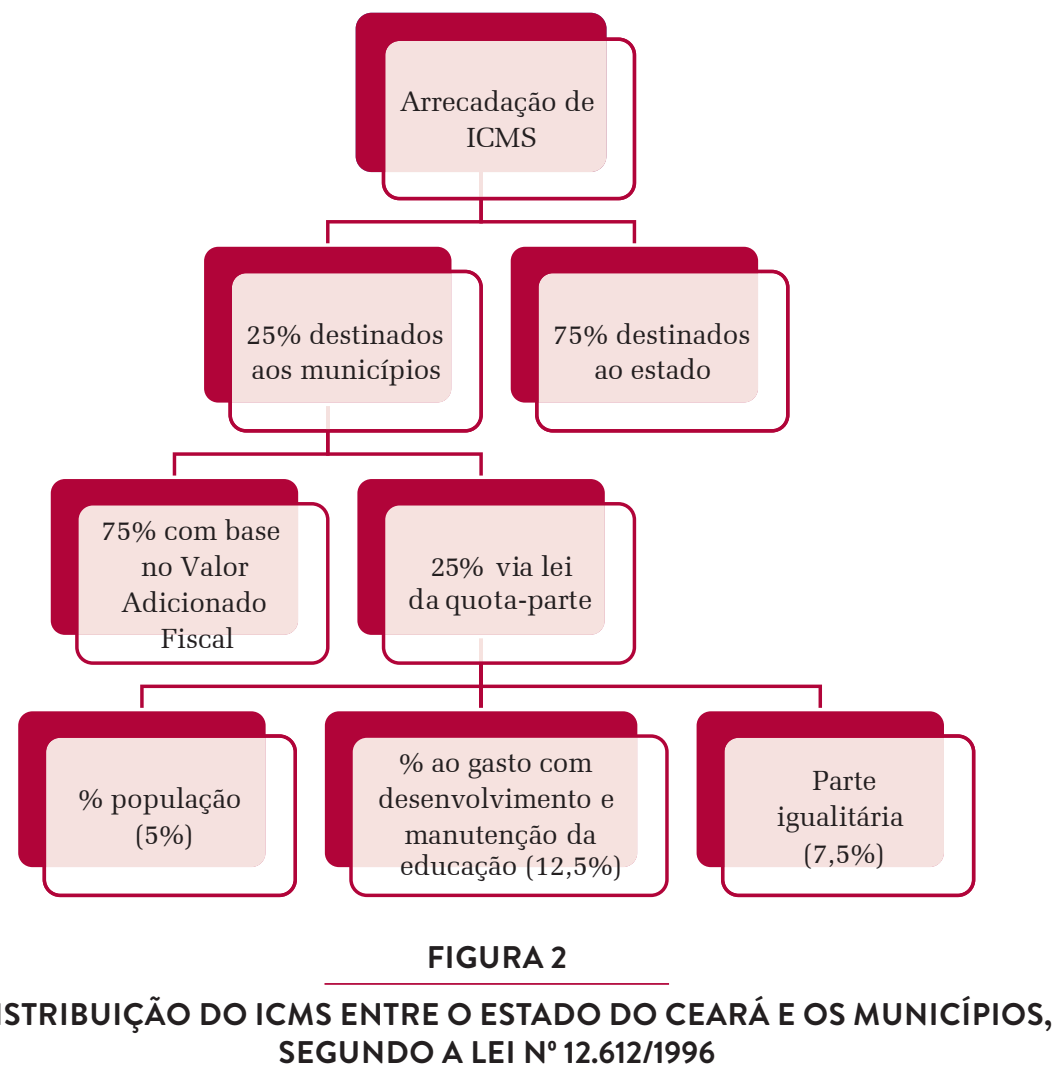

Fonte: Elaboração própria.

Quanto à proporcionalidade da população, utiliza-se a relação existente entre a população do município e a total do estado, medida segundo dados fornecidos pela Fundação Instituto Brasileiro de Geografia e Estatística (IBGE). A parte igualitária corresponde à quota a ser distribuída equitativamente entre todos os municípios. Já a parte educacional condiciona a relação entre o somatório das despesas realizadas pelo município na manutenção e desenvolvimento do ensino ${ }^{3}$ e a receita municipal proveniente de impostos e transferências constitucionais federais e estaduais ${ }^{4}$. Sendo assim, pode-se dizer que a Lei $\mathrm{n}^{0}$ 12.612/1996 adota como critério de distribuição de quota-parte um insumo da função de produção educacional ao utilizar o gasto com educação.

A Lei $\mathrm{n}^{\circ}$ 14.023, de 17 de dezembro de 2007, modifica os dispositivos da Lei $\mathrm{n}^{0}$ 12.612/1996, ao não considerar mais como critérios de rateio do ICMS a proporcionalidade da população, a parte igualitária e o percentual de gasto com manutenção e desenvolvimento do ensino (Holanda et al., 2007; Holanda; Barbosa;

3 Com base nos termos do art. 212 da Constituição Federal e do art. 70 da Lei no 9.394/96.

4 Calculado com base nos dados relativos ao segundo ano civil imediatamente anterior, fornecidos pelo Tribunal de Contas dos Municípios (TCM). 
Costa, 2008; Costa; Paiva, 2009; Paiva, 2017). A divisão da quota-parte passa a se dar com base no Índice Municipal de Qualidade Educacional (IQE), no Índice Municipal de Qualidade da Saúde (IQS) e no Índice Municipal de Qualidade do Meio Ambiente (IQMA), que respondem, respectivamente, por 18\%, 5\% e $2 \%$, como se observa na Figura 3.

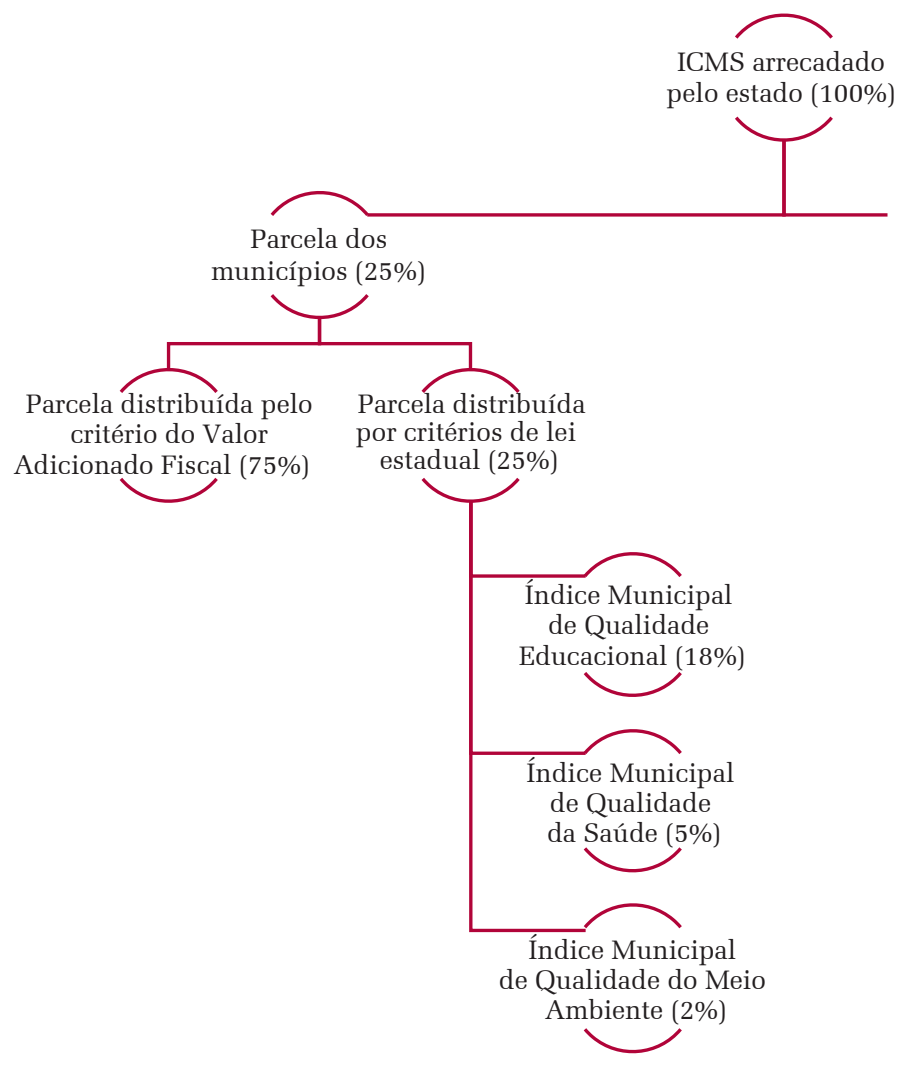

FIGURA 3

A DISTRIBUIÇÃO DA QUOTA-PARTE DO ICMS ENTRE O GOVERNO DO ESTADO DO CEARÁ E OS MUNICÍPIOS, SEGUNDO A LEI N ${ }^{\circ} 14.023 / 2007$

Fonte: Elaboração própria.

\section{AS LEIS VIGENTES EM OUTROS ESTADOS BRASILEIROS ${ }^{5}$}

O mecanismo utilizado pelo Ceará vem se popularizando e sendo adotado por outros estados. Aqueles que possuem leis aprovadas que regem a distribuição de recursos do ICMS a partir de indicadores e/ou critérios educacionais são apresentados

\footnotetext{
5 Simões e Araújo (2019) analisam os regimes redistributivos da quota-parte do ICMS destinada aos municípios adotados pelas diferentes unidades da Federação.
} 
no Quadro 1. Conforme pode ser observado, quatro estados - Amapá, Ceará, Minas Gerais e Pernambuco - possuíam leis vigentes durante o período de 2001 a 2017. Todavia, cabe destacar que São Paulo ${ }^{6}$ e Espírito Santo ${ }^{7}$ têm projetos de lei nessa direção, enquanto Acre, Amapá, Pernambuco e Sergipe tiveram alterações nas suas legislações em 2019 e Alagoas, em 2020.

\section{QUADRO 1}

\section{LEIS ESTADUAIS DE QUOTA-PARTE DO ICMS COM FOCO EM EDUCAÇÃO}

\begin{tabular}{|c|c|c|c|}
\hline UF & Ano & Lei & Vinculação à Educação \\
\hline Acre & 2019 & Lei $n^{\circ} 3.532$, de 30 de outubro de 2019 & $14 \%$ \\
\hline Alagoas & 2020 & Lei $\mathrm{n}^{\circ} 8.234$, de 10 de janeiro de 2020 & $5 \%$ \\
\hline Amapá & 1993 & Lei $\mathrm{n}^{\mathrm{o}} 119$, de 22 de novembro de 1993 & - \\
\hline Amapá & 1996 & Lei $n^{\circ} 322$, de 23 de dezembro de 1996 & $2,27 \%$ \\
\hline Amapá & 2019 & Lei $\mathrm{n}^{\mathrm{o}} 120$, de 2 de dezembro de 2019 & $18 \%$ \\
\hline Ceará & 1993 & Lei $n^{0} 12.172$, de 24 de setembro de 1993 & - \\
\hline Ceará & 1996 & Lei $\mathrm{n}^{\circ}$ 12.612, de 7 de agosto de 1996 & $12,5 \%$ \\
\hline Ceará & 2007 & Lei $\mathrm{n}^{\circ} 14.023$, de 17 de dezembro de 2007 & $18 \%$ \\
\hline Ceará & 2015 & Lei $\mathrm{n}^{\mathrm{o}} 15.922$, de 15 de dezembro de 2015 & $18 \%$ \\
\hline Minas Gerais & 2000 & Lei $n^{\circ} 13.803$, de 27 de dezembro de 2000 & $2 \%$ \\
\hline Minas Gerais & 2009 & Lei $\mathrm{n}^{\mathrm{o}}$ 18.030, de 12 de janeiro de 2009 & $2 \%$ \\
\hline Pernambuco & 1990 & Lei $\mathrm{n}^{0} 10.489$, de 2 de outubro de 1990 & $2 \%$ \\
\hline Pernambuco & 2000 & Lei $\mathrm{n}^{\mathrm{o}} 11.899$, de 21 de dezembro de 2000 & $3 \%$ \\
\hline Pernambuco & 2002 & Lei $\mathrm{n}^{0} 12.206$, de 20 de maio de 2002 & $3 \%$ \\
\hline Pernambuco & 2003 & Lei $\mathrm{n}^{\circ} 12.432$, de 29 de setembro de 2003 & $2 \%$ \\
\hline Pernambuco & 2007 & Lei $\mathrm{n}^{\circ} 13.368$, de 14 de dezembro de 2007 & $3 \%$ \\
\hline Pernambuco & 2011 & Lei $\mathrm{n}^{\circ}$ 14.529, de 9 de dezembro 2011 & $10 \%$ \\
\hline Pernambuco & 2019 & Lei $n^{\circ} 16.616$, de 15 de julho de 2019 & $\begin{array}{c}\text { 8\% no ano 2021, com } \\
\text { aumento gradativo até o } \\
\text { ano de } 2026 \text {, que será } 18 \%\end{array}$ \\
\hline Sergipe & 2019 & Lei $n^{\circ} 8.628$, de 5 de dezembro de 2019 & $18 \%$ \\
\hline
\end{tabular}

Fonte: Elaboração própria.

Observa-se que o Ceará ${ }^{8}$, em 1996, já possuía o maior percentual de recursos vinculados a indicador educacional, 12,5\%; o qual foi posteriormente elevado para

${ }_{6}$ O Projeto de Lei no 855 de 2019 cria o Índice de Qualidade da Educação Municipal (IQEM).

7 Em 2017, foi anunciado o "Pacto pela Aprendizagem” no Espírito Santo, o qual deveria vir a modificar a divisão de ICMS entre os municípios capixabas. No entanto, em 2020, esse estado ainda discute a utilização do ICMS como mecanismo de incentivo educacional.

8 O Quadro A1, em apêndice, apresenta a sequência cronológica das leis do regime de repartição da quotaparte do ICMS no Ceará durante o período de 2001 a 2019 e os respectivos links de acesso. 
18\%. Esse mesmo percentual também foi adotado por Amapá (Lei $\mathrm{n}^{0} 120$, de 2 de dezembro de 2019), Pernambuco (Lei no 16.616, de 15 de julho de 2019) e Sergipe (Lei $\mathrm{n}^{\mathrm{o}}$ 8.628, de 5 de dezembro de 2019). Todavia, no caso de Pernambuco, o aumento se dará de forma gradativa até 2026, quando, ceteris paribus, o percentual de recursos da quota-parte do ICMS atingirá 18\%. No Acre, a destinação baseada em critérios educacionais é de 14\% (Lei ${ }^{\circ} 3.532$, de 30 de outubro de 2019), enquanto em Alagoas é de $5 \%$ (Lei $\mathrm{n}^{\circ}$ 8.234, de 10 de janeiro de 2020).

Vale ressaltar que Pernambuco foi o estado com a maior quantidade de alterações legislativas durante o período analisado, sendo sete ao todo. Contudo, a maior parte das modificações se refere a alterações dos parâmetros de distribuição e do percentual destinado aos municípios com base em critérios e indicadores educacionais. Conforme a alteração mais recente, a Lei $\mathrm{n}^{0} 16.616$, de 15 de julho de 2019, os recursos serão distribuídos a partir de uma combinação dos resultados do Sistema de Avaliação da Educação Básica de Pernambuco (Saepe) e de fluxo escolar.

No caso do Amapá, a Lei n ${ }^{0}$ 322, de 23 de dezembro de 1996, regulamentava o mecanismo de incentivo para educação, considerando como parâmetro de distribuição a relação entre o total de alunos atendidos, inclusive os da pré-escola, e a capacidade de atendimento do município. Essa regra previa que fossem destinados entre $2 \%$ e $3 \%$ da quota-parte segundo esse critério a partir do ano de 1998. A Lei ${ }^{\circ} 120$, de 2 de dezembro de 2019, alterou esse percentual para $18 \%$ e mudou o indicador, sendo que a distribuição passou a ser calculada em função do Índice de Desenvolvimento Escolar de cada município, que é formado pelo produto da taxa de aprovação dos alunos do $1^{\circ}$ ao $5^{\circ}$ ano de ensino fundamental e a média obtida pelos alunos de $2^{\circ}$ e $5^{\circ}$ ano da rede municipal em avaliações de aprendizagem.

Sergipe adota critérios de distribuição semelhantes aos do Amapá. A Lei no 8.628, de 5 de dezembro de 2019, considera a taxa de aprovação dos alunos do $1^{\circ}$ ao $5^{\circ}$ ano do ensino fundamental e a média obtida pelos alunos dos $2^{\circ}$ e $5^{\circ}$ anos da rede municipal em uma avaliação externa própria, o Sistema de Avaliação da Educação Básica de Sergipe (Saese). Já Minas Gerais, por meio da Lei no 18.030, de 12 de janeiro de 2009, destina $2 \%$ dos recursos da quota-parte do ICMS tendo como base a relação entre o total de alunos atendidos e a capacidade de atendimento do município, o mesmo critério da primeira legislação amapaense.

O Quadro 2 apresenta uma síntese das regras atuais de distribuição de recursos da quota-parte do ICMS nos estados que consideram critérios educacionais, reportando o percentual da vinculação e os indicadores observados. 


\section{QUADRO 2}

\section{REGRAS ATUAIS DE DISTRIBUIÇÃO DE RECURSOS DA QUOTA-PARTE DO ICMS NOS ESTADOS QUE CONSIDERAM CRITÉRIOS EDUCACIONAIS}

\begin{tabular}{|c|c|c|c|}
\hline UF & $\begin{array}{l}\text { Base legal/ } \\
\text { ano }\end{array}$ & Vinculação & Indicador \\
\hline Acre & $\begin{array}{l}\text { Lei } \mathrm{n}^{\circ} \\
3.535 / 2019\end{array}$ & $14 \%$ & $\begin{array}{l}\text { Índice de Qualidade da Educação } \\
\text { Municipal, apurado com base nas } \\
\text { notas obtidas pelos municípios no } \\
\text { Ideb, em indicadores oficiais de acesso, } \\
\text { permanência, desempenho e rendimento } \\
\text { dos alunos das redes municipais de } \\
\text { educação básica. }\end{array}$ \\
\hline Alagoas & $\begin{array}{l}\text { Lei }^{\circ} \\
8.234 / 2020\end{array}$ & $5 \%$ & $\begin{array}{l}\text { Mediante aplicação da relação percentual } \\
\text { entre o Índice Municipal de Qualidade } \\
\text { Educacional de Alagoas (IQEAL) do } \\
\text { município e o somatório dos índices do } \\
\text { estado. O IQEAL será composto pelo Ideb } \\
\text { dos anos iniciais do ensino fundamental } \\
\text { de cada município e a variação nos } \\
\text { últimos dois anos do indicador do Ideb } \\
\text { publicados até o último dia do ano-base } \\
\text { de apuração. }\end{array}$ \\
\hline Amapá & $\begin{array}{l}\text { Lei }^{0} \\
\text { 120/2019 }\end{array}$ & $18 \%$ & $\begin{array}{l}\text { Em função do Índice de Desenvolvimento } \\
\text { Escolar de cada município, formado } \\
\text { pela taxa de aprovação dos alunos do } 1^{\circ} \\
\text { ao } 5^{\circ} \text { ano de ensino fundamental e pela } \\
\text { média obtida pelos alunos de } 2^{\circ} \text { e } 5^{\circ} \\
\text { ano da rede municipal em avaliações de } \\
\text { aprendizagem. }\end{array}$ \\
\hline Ceará & $\begin{array}{l}\text { Lei } \mathrm{n}^{\circ} \\
14.023 / 2007 \\
\text { e Decreto } \mathrm{n}^{\circ} \\
\text { 30.796/2011* }\end{array}$ & $18 \%$ & $\begin{array}{l}\text { A taxa de aprovação, as notas dos alunos } \\
\text { e a adesão à avaliação externa (Spaece). }\end{array}$ \\
\hline Minas Gerais & $\begin{array}{l}\text { Lei } \mathrm{n}^{\circ} \\
18.030 / 2009\end{array}$ & $2 \%$ & $\begin{array}{l}\text { Relação entre o total de alunos atendidos } \\
\text { e a capacidade mínima de atendimento do } \\
\text { município. }\end{array}$ \\
\hline Pernambuco & $\begin{array}{l}\text { Lei } \mathrm{n}^{\mathrm{o}} \\
16.616 / 2019\end{array}$ & $\begin{array}{l}8 \% \text { no ano } 2021, \\
\text { aumentando } \\
\text { gradativamente } \\
\text { em } 2 \% \text { até o ano } \\
\text { de } 2026, \text { que } \\
\text { será } 18 \%\end{array}$ & $\begin{array}{l}\text { Combinação dos resultados do Saepe e do } \\
\text { fluxo escolar. }\end{array}$ \\
\hline Sergipe & $\begin{array}{l}\text { Lei } \mathrm{n}^{\circ} \\
8.628 / 2019\end{array}$ & $18 \%$ & $\begin{array}{l}\text { Taxa de aprovação dos alunos do } 1^{\circ} \text { ao } \\
5^{\circ} \text { ano do ensino fundamental e média } \\
\text { obtida pelos alunos dos } 2^{\circ} \text { e } 5^{\circ} \text { anos da } \\
\text { rede municipal em avaliação externa } \\
\text { (Saese). }\end{array}$ \\
\hline
\end{tabular}

Fonte: Elaboração própria.

Nota: O Decreto $\mathrm{n}^{\circ}$ 30.796, de 29 de dezembro de 2011, altera os dispositivos do Decreto $\mathrm{n}^{\circ} 29.881$, de 31 de agosto de 2009 , e dá outras providências. Ele mantém a vinculação dos resultados educacionais em 18\%, conforme o IQE. 


\section{AS EVIDÊNCIAS EMPÍRICAS DA INTERVENÇÃO VIA QUOTA-PARTE DO "ICMS-EDUCACIONAL"}

As evidências empíricas relativas ao efeito do rateio da quota-parte do ICMS a partir de critérios educacionais são escassas para a maioria dos casos e encontram-se dispersas pela literatura. A exemplo disso, não foram encontrados estudos que avaliem os resultados da lei do Amapá, de modo que não é possível conhecer seus efeitos. Em outros trabalhos que abordam esse tipo de política, não são empregadas técnicas que visam aferir seu impacto, por exemplo, o estudo de Sobral e Silva Júnior (2014) que analisou o caso pernambucano no período de 2004 a 2009. Os autores utilizaram a metodologia de cadeias de Markov para avaliar a probabilidade de os municípios alterarem seu padrão de recebimento de ICMS, o que sinalizaria que os agentes públicos estariam reagindo ao incentivo econômico gerado pela política. Concluem que, no que se refere à dimensão educacional, houve uma baixa mobilidade dos municípios indicando que não teve premiação adequada do mérito nesse critério.

Também buscando avaliar a implementação da lei de rateio do ICMS, Maranduba Júnior e Almeida (2009) investigam se existe convergência dos repasses entre municípios de Minas Gerais entre 2001 e 2005 e, a partir de uma análise exploratória espacial, não verificam o efeito redistributivo proposto pela política. Ainda para o caso mineiro, Wanderley (2005) utiliza um painel de efeitos fixos com variável instrumental para medir o impacto da lei sobre os indicadores empregados como critério de rateio e conclui que as transferências contribuíram para elevação da frequência escolar e redução da taxa de analfabetismo. Brunozi Júnior et al. (2008) investigam se a lei do ICMS em Minas Gerais está alcançando seus objetivos e concluem que houve uma queda nas taxas de atendimento, conclusão e aprovação entre 2000 e 2005. Brunozi Júnior et al. (2011), por meio de uma análise de cluster, não observam o efeito das transferências sobre o grau de desenvolvimento da oferta de serviços em educação e saúde.

Existe uma maior diversidade de estudos sobre as leis cearenses (Nogueira, 2012; Petterini; Irffi, 2013; Brandão, 2014; Franca, 2014; Garcia; Simonassi; Costa, 2015; Lopes, 2017; Carneiro; Irffi, 2018a), seja em termos de estratégias ou de hipóteses para analisar os efeitos da Lei $\mathrm{n}^{0}$ 12.612/1996 e da Lei $\mathrm{n}^{0}$ 14.023/2007. Carneiro e Irffi (2018a), por exemplo, traçam um paralelo entre as duas legislações que vigoraram no estado, a Lei $\mathrm{n}^{\circ}$ 12.612/1996, com vigência entre 1997 e 2007, e a Lei n ${ }^{\circ}$ 14.023/2007, que vigorou a partir de então. Os autores concluem que a legislação mais recente levou a ganhos de desempenho dos alunos, ao passo que a regra anterior não mostrou efeito sobre esse indicador. Esses resultados vão ao encontro dos obtidos por Petterini e Irffi (2013) e Brandão (2014).

Em termos metodológicos, Petterini e Irffi (2013) partiram da abordagem de resultados potenciais para avaliar os efeitos da política de rateio do ICMS sobre os municípios cearenses, comparando-os com os baianos, que não foram afetados por nenhuma política semelhante. E, para estimar os impactos da Lei $\mathrm{n}^{0}$ 14.023/2007, 
os autores utilizam o método de Diferença-em-Diferenças (DD) considerando os resultados dos anos de 2007 (pré-tratamento) e 2009 (pós-tratamento).

Brandão (2014) adota metodologia semelhante à do estudo de Petterini e Irffi (2013), entretanto, analisa as taxas de variações nos anos de 2005 e 2007 (pré-tratamento) e 2009 e 2011 (pós-tratamento). Outro diferencial foi a realização de outras duas análises complementares em que, no grupo de tratamento, foram separados (i) os municípios ganhadores e perdedores de recursos da quota-parte do ICMS após a mudança da lei; e (ii) os municípios $20 \%$ mais ricos e os $20 \%$ mais pobres em relação ao PIB per capita. Quanto aos resultados, destaca-se que mesmo os municípios que perderam recursos com a mudança nas regras de distribuição de ICMS melhoraram sua performance na educação e, ainda, que os municípios mais pobres aumentaram o desempenho educacional, diminuindo a diferença de proficiência se comparada aos mais ricos.

Fazendo uma análise relativa a alunos, Carneiro e Irffi (2018a) avaliaram o impacto dos dois modelos de políticas estaduais de incentivo aos gestores municipais que se propuseram a melhorar a educação no Ceará. Primeiramente, a Lei nº 12.612/1996, em que a transferência de recursos era condicionada à proporção de gastos educacionais (ou seja, insumos educacionais - inputs), depois a Lei $\mathrm{n}^{0} 14.023 / 2007$, em que o condicionante era a melhora de resultados educacionais (outputs), mensurados pelos exames do Spaece e pelas taxas de aprovação. O período de análise engloba os anos de 1995 até 2009. Os resultados sugerem a superioridade dos incentivos gerados pela Lei $\mathrm{n}^{\mathrm{o}}$ 14.023/2007 em relação à Lei $\mathrm{n}^{0}$ 12.612/1996 em promover ganhos de aprendizado entre os alunos. Cabe ressaltar que esta lei visava elevar o atendimento pelos municípios, de modo que a ausência de resultados sobre o desempenho não desabona sua funcionalidade para os objetivos aos quais se propôs.

Segundo Nogueira (2012) e Franca (2014), a Lei n ${ }^{0}$ 14.023/2007 também apresenta evidências de uma melhor distribuição de recursos entre os municípios cearenses. Nogueira (2012) faz uma análise exploratória dos dados referentes à quota-parte do ICMS entre 2008 e 2010, mostrando como a distribuição se modificou com a introdução da nova metodologia de cálculo, tornando-se mais equitativa. Franca (2014) utiliza dados de 2009 e 2011 para averiguar se houve uma convergência da quota-parte per capita recebida pelos municípios. Complementarmente, buscou também identificar quais variáveis afetam a probabilidade de um município ser beneficiado pela nova lei e avaliar os efeitos da política. Para cumprir com os objetivos, esse autor utilizou, além do método de DD, a beta convergência e um modelo logit. Como principais resultados, encontrou uma convergência da quota-parte per capita repassada aos municípios, diminuindo, assim, a desigualdade na distribuição dos recursos do ICMS. Os municípios mais beneficiados com a referida lei foram os de população pequena, mercado formal de trabalho menos desenvolvido, indicadores educacionais elevados e reduzida proporção de pobres. Por fim, não houve impacto da lei sobre os indicadores sociais.

Garcia, Simonassi e Costa (2015) também investigam o efeito da mudança nas regras do cálculo da quota-parte do ICMS sobre os investimentos das prefeituras cearenses 
nas áreas de ensino fundamental e saúde. O estudo usa as técnicas de estimação de dados em painel para os anos entre 2006 e 2010, entretanto, não utiliza a estratégia de comparação com um grupo de controle. Os autores concluem que houve uma ligeira elevação da despesa com ensino fundamental nos anos posteriores à política.

Ainda buscando investigar os efeitos da Lei $\mathrm{n}^{0}$ 14.023/2007, Lopes (2017) emprega o método de DD com propensity score matching (PSM) aplicado aos dados censitários de 2000 e 2010, tomando como grupo de controle outros municípios da região nordeste, e conclui que a política contribuiu para a redução do atraso escolar, mas sem elevar os gastos totais com educação ${ }^{9}$.

O Quadro 3 sumariza os estudos que investigam os efeitos de quota-parte do ICMS sobre indicadores educacionais, descrevendo os grupos de comparação, a lei analisada e sua vigência, bem como apresenta uma síntese dos resultados.

\section{QUADRO 3}

\section{EVIDÊNCIAS EMPÍRICAS SOBRE AS LEIS QUE UTILIZAM CRITÉRIOS EDUCACIONAIS PARA DISTRIBUIR RECURSOS DA QUOTA-PARTE MUNICIPAL DO ICMS}

\begin{tabular}{|c|c|c|c|c|c|c|}
\hline \multirow{2}{*}{ UF } & \multirow{2}{*}{ Lei } & \multirow{2}{*}{ Vigência } & \multirow{2}{*}{ Autores } & \multicolumn{2}{|r|}{ Grupo } & \multirow{2}{*}{ Conclusão } \\
\hline & & & & Tratamento & Controle & \\
\hline Amapá & 1996 & 1998 a 2018 & - & - & - & - \\
\hline \multirow{8}{*}{ Ceará } & 1996 & 1997 a 2007 & $\begin{array}{l}\text { Carneiro e } \\
\text { Irffi (2018a) }\end{array}$ & $\begin{array}{c}\text { Alunos das } \\
\text { escolas públicas } \\
\text { municipais do } \\
\text { Ceará }\end{array}$ & $\begin{array}{c}\text { Alunos das escolas } \\
\text { municipais dos demais } \\
\text { estados brasileiros (exceto } \\
\text { Amapá, Pernambuco e } \\
\text { Minas Gerais) }\end{array}$ & $\begin{array}{l}\text { Não observa } \\
\text { efeito sobre o } \\
\text { desempenho }\end{array}$ \\
\hline & \multirow{7}{*}{2007} & \multirow{7}{*}{2008 a 2018} & $\begin{array}{l}\text { Petterini e } \\
\text { Irffi (2013) }\end{array}$ & $\begin{array}{l}\text { Municípios } \\
\text { cearenses }\end{array}$ & Municípios baianos & \multirow{2}{*}{$\begin{array}{c}\text { Efeito positivo } \\
\text { sobre o } \\
\text { desempenho }\end{array}$} \\
\hline & & & $\begin{array}{l}\text { Brandão } \\
\text { (2014) }\end{array}$ & $\begin{array}{l}\text { Municípios } \\
\text { cearenses }\end{array}$ & $\begin{array}{c}\text { Municípios do Piauí, Rio } \\
\text { Grande do Norte, Paraíba } \\
\text { e Pernambuco }\end{array}$ & \\
\hline & & & $\begin{array}{l}\text { Carneiro e } \\
\text { Irffi (2018a) }\end{array}$ & $\begin{array}{c}\text { Alunos das } \\
\text { escolas públicas } \\
\text { municipais do } \\
\text { Ceará }\end{array}$ & $\begin{array}{c}\text { Alunos das escolas } \\
\text { municipais dos demais } \\
\text { estados brasileiros (exceto } \\
\text { Amazonas, Pernambuco e } \\
\text { Minas Gerais) }\end{array}$ & $\begin{array}{l}\text { Houve um } \\
\text { aumento médio } \\
\text { da proficiência } \\
\text { em português e } \\
\text { em matemática. }\end{array}$ \\
\hline & & & $\begin{array}{c}\text { Nogueira } \\
\text { (2012) }\end{array}$ & - & - & \multirow{2}{*}{$\begin{array}{l}\text { Melhor } \\
\text { distribuição dos } \\
\text { recursos }\end{array}$} \\
\hline & & & Franca (2014) & $\begin{array}{l}\text { Municípios } \\
\text { cearenses }\end{array}$ & $\begin{array}{c}\text { Municípios } \\
\text { pernambucanos }\end{array}$ & \\
\hline & & & $\begin{array}{l}\text { Garcia, } \\
\text { Simonassi e } \\
\text { Costa (2015) }\end{array}$ & - & - & \multirow{2}{*}{$\begin{array}{l}\text { Não verifica } \\
\text { aumento dos } \\
\text { recursos }\end{array}$} \\
\hline & & & Lopes (2017) & $\begin{array}{l}\text { Municípios } \\
\text { cearenses }\end{array}$ & $\begin{array}{l}\text { Municípios da região } \\
\text { nordeste, exceto: Piauí, } \\
\text { Paraíba e Pernambuco }\end{array}$ & \\
\hline
\end{tabular}

\footnotetext{
9 Os resultados também apontam para redução na mortalidade infantil sem uma elevação dos gastos municipais totais com saúde.
} 


\section{QUADRO 3}

\section{EVIDÊNCIAS EMPÍRICAS SOBRE AS LEIS QUE UTILIZAM CRITÉRIOS EDUCACIONAIS PARA DISTRIBUIR RECURSOS DA QUOTA-PARTE MUNICIPAL DO ICMS}

\begin{tabular}{|c|c|c|c|c|c|c|}
\hline \multirow{2}{*}{ UF } & \multirow{2}{*}{ Lei } & \multirow{2}{*}{ Vigência } & \multirow{2}{*}{ Autores } & \multicolumn{2}{|r|}{ Grupo } & \multirow{2}{*}{ Conclusão } \\
\hline & & & & Tratamento & Controle & \\
\hline \multirow{3}{*}{ Pernambuco } & 2000 & 2002 a 2007 & \multirow[b]{2}{*}{$\begin{array}{l}\text { Sobral e } \\
\text { Silva Júnior } \\
\text { (2014) }\end{array}$} & - & - & \multirow{2}{*}{$\begin{array}{c}\text { Não houve } \\
\text { premiação } \\
\text { adequada do } \\
\text { mérito no critério } \\
\text { educacional }\end{array}$} \\
\hline & 2007 & 2008 a 2012 & & - & - & \\
\hline & 2011 & 2013 a 2018 & - & - & - & - \\
\hline \multirow{4}{*}{ Minas Gerais } & \multirow{4}{*}{1995} & \multirow{4}{*}{1996 a 2018} & $\begin{array}{l}\text { Wanderley } \\
\text { (2005) }\end{array}$ & $\begin{array}{l}\text { Municípios de } \\
\text { Minas Gerais }\end{array}$ & $\begin{array}{l}\text { Municípios dos estados } \\
\text { limítrofes }\end{array}$ & $\begin{array}{c}\text { Efeito positivo } \\
\text { sobre a } \\
\text { frequência } \\
\text { escolar e a } \\
\text { redução da taxa } \\
\text { de analfabetismo }\end{array}$ \\
\hline & & & $\begin{array}{l}\text { Maranduba } \\
\text { Júnior e } \\
\text { Almeida } \\
\text { (2009) }\end{array}$ & - & - & $\begin{array}{l}\text { Não encontra } \\
\text { convergência } \\
\text { dos repasses } \\
\text { no critério } \\
\text { educacional }\end{array}$ \\
\hline & & & $\begin{array}{c}\text { Brunozi } \\
\text { Júnior et al. } \\
\text { (2008) }\end{array}$ & $\begin{array}{l}\text { Municípios de } \\
\text { Minas Gerais }\end{array}$ & $\begin{array}{l}\text { Municípios de Minas } \\
\text { Gerais }\end{array}$ & $\begin{array}{l}\text { Efeito negativo } \\
\text { sobre a qualidade } \\
\text { da educação }\end{array}$ \\
\hline & & & $\begin{array}{l}\text { Brunozi } \\
\text { Júnior et al. } \\
\text { (2011) }\end{array}$ & $\begin{array}{l}\text { Municípios de } \\
\text { Minas Gerais }\end{array}$ & $\begin{array}{c}\text { Municípios de Minas } \\
\text { Gerais }\end{array}$ & $\begin{array}{c}\text { Não observa } \\
\text { efeito sobre a } \\
\text { oferta de serviços }\end{array}$ \\
\hline
\end{tabular}

Fonte: Elaboração própria.

\section{EVOLUÇÃO DOS INDICADORES DA EDUCAÇÃO PÚBLICA MUNICIPAL NO CEARÁ}

Para analisar os indicadores de desempenho educacional dos municípios cearenses, utilizam-se informações da Secretaria de Educação do Estado do Ceará - Seduc (Spaece Alfa $-2^{\circ}$ ano do EF e Spaece $-5^{\circ}$ ano do EF, Língua Portuguesa e Matemática) e do Instituto Nacional de Estudos e Pesquisas Educacionais Anísio Teixeira (Inep), aferidas a partir do Censo Escolar (taxa de aprovação, taxa de reprovação e taxa de abandono $)^{10}$, além do Ideb. Cabe destacar que os dados são para os anos iniciais, ou seja, do $1^{\circ}$ ao $5^{\circ}$ ano do EF.

\footnotetext{
${ }^{10}$ As sinopses estatísticas da educação básica referentes aos indicadores de fluxo escolar disponibilizam informações desagregadas por município somente a partir de 2007. Para mais informações, vide o site: http://portal.inep.gov.br/web/guest/sinopses-estatisticas-da-educacao-basica.
} 
Em relação aos dados empíricos, o Quadro 4 descreve as informações, o período e a fonte utilizados. A evolução dos indicadores é realizada a partir de estatísticas descritivas (média, desvio padrão, mediana, máximo e mínimo) para cada indicador e para cada ano.

QUADRO 4

INFORMAÇÕES SOBRE OS INDICADORES EDUCACIONAIS PARA OS ANOS INICIAIS DO ENSINO FUNDAMENTAL

\begin{tabular}{|c|c|c|c|}
\hline $\begin{array}{c}\text { Dados } \\
\text { Educacionais }\end{array}$ & Descrição & Período & Fonte \\
\hline Spaece Alfa & $\begin{array}{l}\text { Spaece Alfabetização, } 2^{\circ} \text { ano do ensino } \\
\text { fundamental }\end{array}$ & 2007 a $2017^{*}$ & Seduc \\
\hline \multirow{2}{*}{$\begin{array}{l}\text { Spaece }-5^{\circ} \\
\text { ano do ensino } \\
\text { fundamental }\end{array}$} & Língua Portuguesa & 2008 a 2017 & \multirow[b]{2}{*}{ Seduc } \\
\hline & Matemática & 2008 a 2017 & \\
\hline Ideb & $\begin{array}{l}\text { Resultados do Ideb do } 5^{\circ} \text { ano do ensino } \\
\text { fundamental }\end{array}$ & 2005 a $2017^{* *}$ & Inep \\
\hline $\begin{array}{l}\text { Taxa de } \\
\text { aprovação }\end{array}$ & $\begin{array}{l}\text { Taxa de aprovação dos anos iniciais } \\
\text { (do } 1^{\circ} \text { ao } 5^{\circ} \text { ) }\end{array}$ & 2007 a 2017 & Inep \\
\hline $\begin{array}{l}\text { Taxa de } \\
\text { reprovação }\end{array}$ & $\begin{array}{l}\text { Taxa de reprovação dos anos iniciais } \\
\text { (do } 1^{\circ} \text { ao } 5^{\circ} \text { ) }\end{array}$ & 2007 a 2017 & Inep \\
\hline Taxa de abandono & $\begin{array}{l}\text { Taxa de abandono dos anos iniciais } \\
\left(\text { do } 1^{\circ} \text { ao } 5^{\circ} \text { ) }\right.\end{array}$ & 2007 a 2017 & Inep \\
\hline
\end{tabular}

Fonte: Elaboração própria com base nos dados do Spaece/Seduc, Ideb/Inep e Censo da Educação Básica/Inep. Nota: * As informações não foram disponibilizadas para o ano de 2011.

** Os resultados do Ideb são bianuais.

Inicialmente, são apresentadas as medidas de rendimento (taxa de aprovação, taxa de reprovação e taxa de abandono) para os anos iniciais (do $1^{\circ}$ ao $5^{\circ}$ ) do ensino fundamental, por ano de apuração. As taxas de rendimento são informadas pelas escolas durante a segunda etapa do Censo Escolar e revelam a situação dos alunos ao final do ano letivo por meio dos seguintes resultados: a) aprovados ou reprovados, com base nos requisitos de avaliação de desempenho estabelecidos pela própria escola; ou b) se deixaram de frequentar a escola ao longo do ano letivo, caracterizando, assim, o abandono.

A Tabela 1 apresenta as estatísticas para a taxa de aprovação dos anos iniciais. Verifica-se um aumento médio de 12 pontos percentuais entre os anos de 2007 a 2017. Além disso, 50\% dos municípios cearenses tiveram, em 2007, taxa de aprovação igual ou menor a $84,9 \%$ nos anos iniciais; entretanto, em 2017, a mediana chegou a 97,6\%. Esse crescimento foi acompanhado de uma redução do desvio padrão, ou seja, diminuiu a dispersão da taxa de aprovação entre os municípios cearenses, tornando-os menos desiguais. Verifica-se, ainda, um aumento considerável em relação à menor taxa de aprovação, de 62,4\%, em 2007, para 84,9\%, em 2017. 
TABELA 1

TAXA DE APROVAÇÃO DOS ANOS INICIAIS (DO $1^{\circ}$ AO $5^{\circ}$ ) DO ENSINO FUNDAMENTAL NOS MUNICÍPIOS CEARENSES - 2007-2017 (\%)

\begin{tabular}{|c|r|r|r|r|r|r|r|r|r|r|r|}
\hline $\begin{array}{c}\text { Medidas } \\
\text { Descritivas }\end{array}$ & $\mathbf{2 0 0 7}$ & $\mathbf{2 0 0 8}$ & $\mathbf{2 0 0 9}$ & $\mathbf{2 0 1 0}$ & $\mathbf{2 0 1 1}$ & $\mathbf{2 0 1 2}$ & $\mathbf{2 0 1 3}$ & $\mathbf{2 0 1 4}$ & $\mathbf{2 0 1 5}$ & $\mathbf{2 0 1 6}$ & $\mathbf{2 0 1 7}$ \\
\hline $\begin{array}{c}\text { Média } \\
\text { Desvio }\end{array}$ & 84,5 & 85,7 & 88,8 & 90,9 & 92,8 & 93,0 & 95,3 & 95,6 & 96,3 & 95,7 & 96,8 \\
\hline Padrão & 7,2 & 7,0 & 6,1 & 5,2 & 4,3 & 4,2 & 3,5 & 3,6 & 3,5 & 3,9 & 3,2 \\
\hline Mediana & 84,9 & 86,5 & 90,0 & 91,6 & 93,4 & 93,6 & 95,9 & 96,4 & 97,4 & 96,8 & 97,6 \\
\hline Máximo & 99,8 & 99,9 & 100,0 & 100,0 & 99,9 & 99,9 & 100,0 & 99,8 & 100,0 & 100,0 & 100,0 \\
\hline Mínimo & 62,4 & 62,3 & 64,8 & 74,4 & 81,0 & 81,6 & 80,5 & 83,6 & 83,7 & 83,2 & 84,9 \\
\hline
\end{tabular}

Fonte: Elaboração própria com base nos dados do Censo da Educação Básica/Inep.

Quanto à taxa de reprovação (Tabela 2) dos anos iniciais, observa-se uma redução significativa, uma vez que, em 2007 , foi de $12,9 \%$ e, em 2017 , de $2,8 \%$; ou seja, uma diminuição de 10 pontos percentuais. Também se verifica uma queda na dispersão da taxa entre os municípios cearenses, bem como uma redução da taxa máxima e da mediana. Em síntese, pode-se dizer que a taxa de reprovação dos anos iniciais (do $1^{\circ}$ ao $5^{\circ}$ ) do ensino fundamental nesses municípios caiu de forma considerável e foi acompanhada da redução da desigualdade.

Ainda em relação às medidas de rendimento, observa-se na Tabela 3 que a taxa de abandono do $1^{\circ}$ ao $5^{\circ}$ ano do EF diminuiu durante o período de 2007 a 2017. Nota-se que a média era de 2,6\%, em 2007, e chegou a 0,4\%, em 2017, enquanto a redução da taxa de abandono máxima foi de mais de 10 pontos percentuais, uma vez que, em 2007, era de 13,2\% em Penaforte e, em 2017, de 2,5\% em Ipaumirim. Essa redução média é acompanhada de diminuição da dispersão da taxa de abandono entre os municípios cearenses, indicada pela queda no desvio padrão.

De maneira geral, pode-se inferir, a partir das medidas de rendimento dos anos iniciais do EF, que os municípios cearenses apresentam aumento na taxa de aprovação e redução nas taxas de reprovação e abandono. Esse aumento é acompanhado pela diminuição da dispersão nas três medidas, o que denota uma convergência entre os municípios nas medidas de rendimento.

TABELA 2

TAXA DE REPROVAÇÃO DOS ANOS INICIAIS (DO $1^{\circ} A O 5^{\circ}$ ) DO ENSINO FUNDAMENTAL NOS MUNICÍPIOS CEARENSES - 2007/2017 (\%)

\begin{tabular}{|l|r|r|r|r|r|r|r|r|r|r|r|}
\hline $\begin{array}{c}\text { Medidas } \\
\text { Descritivas }\end{array}$ & 2007 & 2008 & 2009 & 2010 & 2011 & 2012 & 2013 & 2014 & 2015 & 2016 & 2017 \\
\hline Média & 12,9 & 12,0 & 9,5 & 7,8 & 6,2 & 6,1 & 4,0 & 3,8 & 3,3 & 3,8 & 2,8 \\
\hline Desvio Padrão & 6,4 & 6,1 & 5,3 & 4,6 & 3,9 & 3,8 & 3,2 & 3,2 & 3,2 & 3,5 & 2,9 \\
\hline Mediana & 12,6 & 11,4 & 8,8 & 7,3 & 5,6 & 5,5 & 3,4 & 2,9 & 2,3 & 2,8 & 1,8 \\
\hline Máximo & 31,7 & 31,8 & 30,1 & 19,5 & 15,8 & 16,3 & 18,1 & 15,7 & 14,5 & 15,3 & 13,2 \\
\hline Mínimo & 0 & 0 & 0 & 0 & 0 & 0 & 0 & 0,1 & 0 & 0 & 0 \\
\hline
\end{tabular}

Fonte: Elaboração própria com base nos dados do Censo da Educação Básica/Inep. 
TABELA 3

TAXA DE ABANDONO DOS ANOS INICIAIS (DO $1^{\circ}$ AO $5^{\circ}$ ) DO ENSINO FUNDAMENTAL NOS MUNICÍPIOS CEARENSES - 2007/2017 (\%)

\begin{tabular}{|l|r|r|r|r|r|r|r|r|r|r|r|}
\hline $\begin{array}{c}\text { Medidas } \\
\text { Descritivas }\end{array}$ & $\mathbf{2 0 0 7}$ & $\mathbf{2 0 0 8}$ & $\mathbf{2 0 0 9}$ & $\mathbf{2 0 1 0}$ & $\mathbf{2 0 1 1}$ & $\mathbf{2 0 1 2}$ & $\mathbf{2 0 1 3}$ & $\mathbf{2 0 1 4}$ & $\mathbf{2 0 1 5}$ & $\mathbf{2 0 1 6}$ & $\mathbf{2 0 1 7}$ \\
\hline Média & 2,6 & 2,4 & 1,7 & 1,3 & 1,0 & 1,0 & 0,6 & 0,6 & 0,4 & 0,5 & 0,4 \\
\hline Desvio Padrão & 1,8 & 1,6 & 1,3 & 1,0 & 0,9 & 0,8 & 0,6 & 0,6 & 0,5 & 0,5 & 0,5 \\
\hline Mediana & 2,3 & 2,1 & 1,5 & 1,1 & 0,8 & 0,7 & 0,5 & 0,5 & 0,3 & 0,3 & 0,2 \\
\hline Máximo & 13,2 & 10,1 & 6,5 & 6,7 & 4,2 & 5,0 & 2,8 & 4,0 & 2,2 & 2,4 \\
\hline Mínimo & 0 & 0 & 0 & 0 & 0 & 0 & 0 & 0 & 0 & 0 \\
\hline
\end{tabular}

Fonte: Elaboração própria com base nos dados do Censo da Educação Básica/Inep.

Em relação às medidas de desempenho, primeiramente são apresentadas as descritivas dos resultados de proficiência em alfabetização no $2^{\circ}$ ano do EF, seguidas pelos resultados do $5^{\circ}$ ano nas proficiências em Língua Portuguesa e Matemática, bem como do Ideb para os anos iniciais dessa etapa de ensino. Além disso, no caso do Spaece Alfa e do $5^{\circ}$ ano do EF, analisa-se o padrão de desempenho.

Os padrões de desempenho são categorias definidas a partir de cortes numéricos que agrupam os níveis da escala de proficiência, entre 0 e 500 pontos, com base nas metas educacionais estabelecidas pelo Spaece Alfa para o $2^{\circ}$ ano do EF. Esses cortes dão origem a cinco padrões de desempenho: Não Alfabetizado (0 até 75 pontos), Alfabetização Incompleta (75 até 100 pontos), Intermediário (100 até 125 pontos), Suficiente (125 até 150 pontos) e Desejável (acima de 150 pontos), os quais apresentam o perfil de desempenho dos alunos ${ }^{11}$.

No caso do Spaece Alfa, observa-se pela Tabela 4 que, em 2007, três municípios (Abaiara, Baixio e Senador Sá) apresentavam o padrão “Não Alfabetizado”, enquanto menos de 10\%, o padrão "Desejável”. Em 2008, apenas Ibaretama estava no padrão "Não Alfabetizado". A partir do ano de 2009, nenhum município teve seu padrão de desempenho classificado como "Não Alfabetizado" ou "Alfabetização Incompleta". No mesmo ano, também foi a primeira vez que um maior número de municípios foi classificado com padrão "Desejável", e não apenas "Suficiente". Desde então, a quantidade daqueles com padrão "Suficiente" apresenta uma diminuição, passando de 79, em 2009, para 2, em 2017, enquanto o número de municípios com padrão “Desejável” aumentou, passando de 83, em 2009, para 182, em 2017, o que corresponde a aproximadamente 99\% dos municípios, ou seja, as notas estão em pelo menos 150 pontos na escala do Spaece Alfa.

\footnotetext{
${ }^{11}$ Para mais informações, acesse: http://www.spaece.caedufjf.net/.
} 
TABELA 4

NÚMERO DE MUNICÍPIOS DO CEARÁ POR PADRÃO DE DESEMPENHO NO SPAECE ALFA, $2^{\circ}$ ANO DO ENSINO FUNDAMENTAL - 2007/2017*

\begin{tabular}{|l|r|r|r|r|r|r|r|r|r|r|}
\hline Padrão de Desempenho & $\mathbf{2 0 0 7}$ & $\mathbf{2 0 0 8}$ & $\mathbf{2 0 0 9}$ & $\mathbf{2 0 1 0}$ & $\mathbf{2 0 1 2}$ & $\mathbf{2 0 1 3}$ & $\mathbf{2 0 1 4}$ & $\mathbf{2 0 1 5}$ & $\mathbf{2 0 1 6}$ & $\mathbf{2 0 1 7}$ \\
\hline Não Alfabetizado & 3 & 1 & 0 & 0 & 0 & 0 & 0 & 0 & 0 & 0 \\
\hline Alfabetização Incompleta & 36 & 9 & 0 & 0 & 0 & 0 & 0 & 0 & 0 & 0 \\
\hline Intermediário & 96 & 82 & 22 & 1 & 0 & 0 & 0 & 0 & 0 & 0 \\
\hline Suficiente & 35 & 69 & 79 & 42 & 35 & 18 & 11 & 4 & 4 & 2 \\
\hline Desejável & 14 & 23 & 83 & 141 & 149 & 166 & 173 & 180 & 180 & 182 \\
\hline
\end{tabular}

Fonte: Elaboração própria com base nos dados do Spaece/Seduc.

Nota: * As informações não foram disponibilizadas para o ano de 2011

Em relação à performance na escala do Spaece Alfa, verifica-se pela Tabela $5 \mathrm{um}$ aumento significativo na média, na mediana e nas notas máxima e mínima ao longo do período de 2007 a 2017. A média, por exemplo, acresceu 90 pontos entre os anos analisados; enquanto o aumento na nota mínima foi de 80 pontos na escala do Spaece Alfa. Entretanto, ainda em 2017, dois municípios estão aquém do padrão "Desejável" (pelo menos 150 pontos no Spaece Alfa). Observa-se que a mediana também teve um crescimento de 84 pontos ao longo do período em tela.

A partir desses dados, pode-se inferir que os níveis de alfabetização dos municípios cearenses apresentam uma melhora significativa. No entanto, apesar de indicadores positivos relacionados à média, à mediana e às notas mínima e máxima, verifica-se que o desvio padrão das notas também aumentou, ou seja, a dispersão em termos de alfabetização acresceu. Sendo assim, pode-se dizer que a alfabetização não apresentou a mesma evolução entre todos os municípios cearenses durante o período de 2007 a 2017.

Os padrões de desempenho da prova de Língua Portuguesa para o $5^{\circ}$ ano do EF são definidos a partir de cortes numéricos que agrupam os níveis da escala de proficiência, definida entre 0 e 500 pontos, com base nas metas educacionais estabelecidas pelo Spaece $^{12}$. Os padrões são classificados em Muito Crítico (0 até 125 pontos), Crítico (125 até 175 pontos), Intermediário (175 até 225 pontos) e Adequado (acima de 225 pontos).

TABELA 5

ESTATÍSTICAS DESCRITIVAS DAS NOTAS NO SPAECE ALFA, $2^{\circ}$ ANO DO ENSINO FUNDAMENTAL - 2007/2017*

\begin{tabular}{|l|r|r|r|r|r|r|r|r|r|r|r|}
\hline Medidas Descritivas & $\mathbf{2 0 0 7}$ & $\mathbf{2 0 0 8}$ & $\mathbf{2 0 0 9}$ & $\mathbf{2 0 1 0}$ & $\mathbf{2 0 1 2}$ & $\mathbf{2 0 1 3}$ & $\mathbf{2 0 1 4}$ & $\mathbf{2 0 1 5}$ & $\mathbf{2 0 1 6}$ & $\mathbf{2 0 1 7}$ \\
\hline Média & 115,6 & 128,4 & 150,9 & 176,9 & 173,2 & 177,6 & 188,1 & 195,9 & 195,2 & 205,3 \\
\hline Desvio Padrão & 21,3 & 21,7 & 26,2 & 32,9 & 27,2 & 29,3 & 30,4 & 33,6 & 29,2 & 32,4 \\
\hline Mediana & 114,1 & 125,0 & 145,6 & 170,3 & 166,6 & 168,1 & 179,6 & 187,1 & 192,7 & 197,9 \\
\hline Máximo & 188,2 & 229,2 & 229,5 & 253,7 & 269,5 & 267,8 & 267,3 & 276,7 & 263,0 & 270,0 \\
\hline Mínimo & 59,4 & 70,8 & 101,9 & 117,5 & 131,4 & 136,3 & 136,8 & 143,9 & 136,2 & 139,0 \\
\hline
\end{tabular}

Fonte: Elaboração própria com base nos dados do Spaece/Seduc.

Nota: * As informações não foram disponibilizadas para o ano de 2011.

\footnotetext{
${ }^{12}$ Para mais informações, acesse: http://www.spaece.caedufjf.net/.
} 
Observa-se pela Tabela 6 que, em 2008, nenhum município apresenta padrão de desempenho "Muito Crítico" ou "Adequado" para a proficiência de Língua Portuguesa do $5^{\circ}$ ano do EF. A partir de 2010, um município se enquadra no padrão de desempenho "Adequado"; nota-se que em 2011, pela primeira vez, há mais municípios no padrão de desempenho "Intermediário" do que no "Crítico”. Verifica-se que, a partir de 2015, nenhum município apresenta padrão de desempenho "Crítico”. Em 2017, o número daqueles com desempenho "Intermediário" e "Adequado" é semelhante. Entre os anos de 2008 a 2017, a quantidade de municípios classificados com padrão de desempenho "Adequado" para proficiência de Língua Portuguesa no $5^{\circ}$ ano do ensino fundamental passou de 0 para 91 , enquanto o número daqueles com padrão "Intermediário” foi de 18 para 93.

TABELA 6

NÚMERO DE MUNICÍPIOS DO CEARÁ POR PADRÃO DE DESEMPENHO NA PROFICIÊNCIA MÉDIA EM LÍNGUA PORTUGUESA, $5^{\circ}$ ANO DO ENSINO FUNDAMENTAL - 2008-2017

\begin{tabular}{|l|r|r|r|r|r|r|r|r|r|r|}
\hline $\begin{array}{c}\text { Padrão de } \\
\text { Desempenho }\end{array}$ & $\mathbf{2 0 0 8}$ & $\mathbf{2 0 0 9}$ & $\mathbf{2 0 1 0}$ & $\mathbf{2 0 1 1}$ & $\mathbf{2 0 1 2}$ & $\mathbf{2 0 1 3}$ & $\mathbf{2 0 1 4}$ & $\mathbf{2 0 1 5}$ & $\mathbf{2 0 1 6}$ & $\mathbf{2 0 1 7}$ \\
\hline Crítico & 166 & 131 & 108 & 21 & 2 & 2 & 1 & 0 & 0 & 0 \\
\hline Intermediário & 18 & 53 & 75 & 150 & 166 & 160 & 141 & 136 & 139 & 93 \\
\hline Adequado & 0 & 0 & 1 & 13 & 16 & 22 & 42 & 48 & 45 & 91 \\
\hline
\end{tabular}

Fonte: Elaboração própria com base nos dados do Spaece/Seduc.

Em relação à proficiência em Língua Portuguesa no $5^{\circ}$ ano do EF, aferida pelo Spaece, pode-se observar, a partir da Tabela 7, um aumento médio expressivo das notas entre os anos de 2008 a 2017 de, aproximadamente, 67 pontos. Verifica-se ainda que o crescimento na nota máxima foi de quase 100 pontos, uma vez que, em 2008, a maior nota foi 195,4 em Sobral, enquanto, em 2017, o município de Ararenda alcançou 292,4 pontos na escala do Spaece. A nota mediana também aumentou, assim como a mínima. Outra questão relevante que merece destaque é o crescimento do desvio padrão da proficiência em Língua Portuguesa de forma considerável, denotando um aumento na dispersão da proficiência dos alunos do $5^{\circ}$ ano do EF.

TABELA 7

ESTATÍSTICAS DESCRITIVAS DAS NOTAS NO SPAECE EM LÍNGUA PORTUGUESA, $5{ }^{\circ}$ ANO DO ENSINO FUNDAMENTAL - 2008/2017

\begin{tabular}{|l|r|r|r|r|r|r|r|r|r|r|}
\hline Medidas Descritivas & $\mathbf{2 0 0 8}$ & $\mathbf{2 0 0 9}$ & $\mathbf{2 0 1 0}$ & $\mathbf{2 0 1 1}$ & $\mathbf{2 0 1 2}$ & $\mathbf{2 0 1 3}$ & $\mathbf{2 0 1 4}$ & $\mathbf{2 0 1 5}$ & $\mathbf{2 0 1 6}$ & $\mathbf{2 0 1 7}$ \\
\hline Média & 163,8 & 168,9 & 173,9 & 190,8 & 201,9 & 204,4 & 212,2 & 216,9 & 216,0 & 231,2 \\
\hline Desvio Padrão & 9,0 & 11,3 & 13,4 & 18,7 & 16,2 & 17,4 & 20,1 & 22,8 & 17,5 & 24,5 \\
\hline Mediana & 162,9 & 167,6 & 171,5 & 186,4 & 198,0 & 200,5 & 205,7 & 209,0 & 212,7 & 224,7 \\
\hline Máximo & 195,4 & 217,5 & 234,1 & 281,5 & 260,4 & 257,7 & 280,9 & 285,5 & 279,2 & 292,4 \\
\hline Mínimo & 145,0 & 145,2 & 148,9 & 160,9 & 173,8 & 168,4 & 171,4 & 180,4 & 181,5 & 181,9 \\
\hline
\end{tabular}

Fonte: Elaboração própria com base nos dados do Spaece/Seduc. 
O padrão de desempenho na prova de Matemática do Spaece para o $5^{\circ}$ ano do EF considera quatro níveis, classificados a partir da nota na escala entre 0 e 500 pontos: Muito Crítico (0 até 225 pontos), Crítico (225 até 275 pontos), Intermediário ( 275 até 325 pontos) e Adequado (acima de 325 pontos). ${ }^{13}$

Em 2008, 97,8\% (180) dos municípios encontravam-se no padrão de desempenho “Crítico" e apenas 1\% no patamar "Intermediário", como se observa na Tabela 8. Além disso, verifica-se que nenhum município foi classificado com padrão "Adequado" em Matemática. Nesse ano, dois municípios, Capistrano e Trairi, apresentaram padrão de desempenho “Muito Crítico”. Já em 2009, apenas Ibaretama se enquadrou nesse padrão. Vale ressaltar que, desde 2010, nenhum município é classificado com desempenho "Muito Crítico".

Em 2017, 68,5\% dos municípios apresentam desempenho "Intermediário", enquanto 28,3\%, "Adequado". No entanto, seis municípios (Caucaia, Ibaretama, Icó, Ipaumirim, Quixada e Umari) estão no patamar "Crítico". Outra característica que vale destacar é que a quantidade de municípios com padrão de desempenho "Adequado" em Matemática é inferior à de Língua Portuguesa (Tabela 6).

\section{TABELA 8}

\section{NÚMERO DE MUNICÍPIOS DO CEARÁ POR PADRÃO DE DESEMPENHO NA PROFICIÊNCIA MÉDIA EM MATEMÁTICA, 5 ANO DO ENSINO FUNDAMENTAL - 2008-2017}

\begin{tabular}{|l|r|r|r|r|r|r|r|r|r|r|}
\hline $\begin{array}{c}\text { Padrão de } \\
\text { Desempenho }\end{array}$ & $\mathbf{2 0 0 8}$ & $\mathbf{2 0 0 9}$ & $\mathbf{2 0 1 0}$ & $\mathbf{2 0 1 1}$ & $\mathbf{2 0 1 2}$ & $\mathbf{2 0 1 3}$ & $\mathbf{2 0 1 4}$ & $\mathbf{2 0 1 5}$ & $\mathbf{2 0 1 6}$ & $\mathbf{2 0 1 7}$ \\
\hline Muito Crítico & 2 & 1 & 0 & 0 & 0 & 0 & 0 & 0 & 0 & 0 \\
\hline Crítico & 180 & 175 & 152 & 75 & 58 & 48 & 17 & 7 & 13 & 6 \\
\hline Intermediário & 2 & 7 & 30 & 96 & 112 & 116 & 132 & 128 & 139 & 126 \\
\hline Adequado & 0 & 1 & 2 & 13 & 14 & 20 & 35 & 49 & 32 & 52 \\
\hline
\end{tabular}

Fonte: Elaboração própria com base nos dados do Spaece/Seduc.

Em relação às notas na prova de Matemática, verifica-se um crescimento na média da proficiência de 74 pontos na escala do Spaece (Tabela 9). O valor mínimo também aumentou, mas ainda não superou o limite do padrão "Muito Crítico" (0 até 225 pontos). Analogamente à proficiência em Língua Portuguesa, verifica-se que ainda existe espaço para melhorar a performance em Matemática na escala do Spaece para o $5^{\circ}$ ano do EF. Assim como em Língua Portuguesa, o desvio padrão da proficiência em Matemática apresentou crescimento significativo, indicando uma maior dispersão das notas entre os municípios cearenses ao longo do período de 2008 a 2017.

${ }^{13}$ Para mais informações, acesse: http://www.spaece.caedufjf.net/. 
TABELA 9

ESTATÍSTICAS DESCRITIVAS DAS NOTAS NO SPAECE EM MATEMÁTICA, $5^{\circ}$ ANO DO ENSINO FUNDAMENTAL - 2008-2017

\begin{tabular}{|l|r|r|r|r|r|r|r|r|r|r|}
\hline \multicolumn{1}{|c|}{ Medidas Descritivas } & $\mathbf{2 0 0 8}$ & $\mathbf{2 0 0 9}$ & $\mathbf{2 0 1 0}$ & $\mathbf{2 0 1 1}$ & $\mathbf{2 0 1 2}$ & $\mathbf{2 0 1 3}$ & $\mathbf{2 0 1 4}$ & $\mathbf{2 0 1 5}$ & $\mathbf{2 0 1 6}$ & $\mathbf{2 0 1 7}$ \\
\hline Média & 165,5 & 175,3 & 189,3 & 209,5 & 212,9 & 216,5 & 226,7 & 236,4 & 228,4 & 239,2 \\
\hline Desvio Padrão & 9,4 & 15,4 & 17,8 & 23,3 & 22,9 & 23,6 & 25,5 & 28,7 & 21,9 & 30,1 \\
\hline Mediana & 164,2 & 172,2 & 185,0 & 203,8 & 205,2 & 209,4 & 218,5 & 228,1 & 222,6 & 230,1 \\
\hline Máximo & 203,9 & 252,1 & 274,8 & 305,5 & 304,1 & 286,9 & 299,0 & 312,6 & 295,1 & 315,7 \\
\hline Mínimo & 147,7 & 149,0 & 162,8 & 169,8 & 175,3 & 177,7 & 182,4 & 192,5 & 187,2 & 183,5 \\
\hline
\end{tabular}

Fonte: Elaboração própria com base nos dados do Spaece/Seduc.

O Ideb é considerado um indicador de qualidade da educação básica no Brasil. Ele é aferido pelo Inep a partir da combinação entre medidas de fluxo e de aprendizagem. Essa combinação visa equilibrar as duas dimensões de maneira a mitigar o gaming na avaliação externa. Caso uma rede de ensino retenha seus alunos para obter melhores resultados na aprendizagem (aferida a partir de avaliações externas - Prova Brasil) no Sistema de Avaliação da Educação Básica (Saeb), o fator fluxo será alterado, indicando a necessidade de melhoria do sistema. Por outro lado, se a rede de ensino apressar a aprovação do aluno sem as devidas competências, o resultado na aprendizagem pode diminuir, o que denota uma baixa qualidade do sistema educacional.

A Tabela 10 apresenta as estatísticas descritivas para o Ideb dos anos iniciais do EF. Verifica-se um aumento na média, na mediana e nas notas máxima e mínima, o que demonstra uma evolução positiva desse índice. Em relação à média, observa-se um crescimento de 3 pontos na escala entre os anos de 2005 a 2017. No entanto, assim como no caso do Spaece do $5^{\circ}$ ano do EF em Língua Portuguesa e Matemática, verifica-se um aumento do desvio padrão do Ideb. Portanto, a melhoria nesse índice não foi apropriada de forma homogênea entre os municípios cearenses, uma vez que se observa um crescimento da dispersão na qualidade educacional dos anos iniciais da educação pública.

A média estabelecida como meta para o Brasil no Ideb dos anos iniciais em 2021 é 6,0, o que corresponde ao patamar educacional dos países da Organização para a Cooperação e Desenvolvimento Econômico (OCDE) no ano de 2009. Nesse ano, a pontuação média dos estudantes dos países que integram a OCDE era de 493 pontos na avaliação de Leitura e de 496 pontos na de Matemática, contra uma média de 412 pontos em Leitura e 386 pontos em Matemática para os alunos brasileiros. Dessa forma, a meta estabelecida objetiva zerar um gap de 16,4\% no teste de Leitura e de 22,2\% no de Matemática, considerando constante o desempenho dos países da OCDE a partir de 2009. Vale ressaltar que, em 2009, Sobral $(6,6)$ e Abaiara $(6,5)$ já apresentavam Ideb superior a 6,0. 
TABELA 10

ESTATÍSTICAS DESCRITIVAS DO IDEB OBSERVADO NOS MUNICÍPIOS DO CEARÁ PARA OS ANOS INICIAIS DO ENSINO FUNDAMENTAL - 2005/2017

\begin{tabular}{|l|r|r|r|r|r|r|r|}
\hline \multicolumn{1}{|c|}{ Medidas Descritivas } & $\mathbf{2 0 0 5}$ & $\mathbf{2 0 0 7}$ & $\mathbf{2 0 0 9}$ & $\mathbf{2 0 1 1}$ & $\mathbf{2 0 1 3}$ & $\mathbf{2 0 1 5}$ & $\mathbf{2 0 1 7}$ \\
\hline Média & 3,1 & 3,4 & 4,0 & 4,8 & 5,1 & 5,9 & 6,1 \\
\hline Desvio Padrão & 0,43 & 0,45 & 0,54 & 0,66 & 0,76 & 0,86 & 0,87 \\
\hline Mediana & 3,1 & 3,4 & 4,0 & 4,7 & 5,0 & 5,7 & 6,0 \\
\hline Máximo & 4,4 & 5,2 & 6,6 & 7,5 & 7,8 & 8,8 & 9,1 \\
\hline Mínimo & 1,7 & 2,3 & 2,5 & 3,3 & 3,6 & 4,1 & 4,2 \\
\hline
\end{tabular}

Fonte: Elaboração própria com base nos dados do Ideb/Inep.

Observa-se pela Tabela 11 que, a cada edição do Ideb, a partir de 2009, aumenta o número de municípios cearenses com patamar educacional da OCDE. Vale ressaltar que Sobral apresenta padrão de desempenho equivalente à média dos países da OCDE desde 2009 e, com exceção de 2011 (Mucambo: 7,5; Sobral: 7,3), possui desde então o maior Ideb do estado.

TABELA 11

NÚMERO DE MUNICÍPIOS DO CEARÁ COM IDEB MAIOR QUE 6,0 (PADRÃO EDUCACIONAL DA OCDE) - 2009/2017

\begin{tabular}{|c|c|}
\hline Ano & Número de Municípios \\
\hline 2009 & 2 \\
\hline 2011 & 8 \\
\hline 2013 & 22 \\
\hline 2015 & 29 \\
\hline 2017 & 84 \\
\hline
\end{tabular}

Fonte: Elaboração própria com base nos dados do Ideb/Inep.

De maneira geral, observa-se uma melhora nos indicadores educacionais dos municípios cearenses, a partir do aumento médio das notas no Spaece Alfa, das proficiências em Língua Portuguesa e Matemática e do Ideb, acompanhado de maiores taxas de aprovação e menores taxas de reprovação e abandono, o que sinaliza uma melhora no quadro educacional cearense. Todavia, apesar dos bons resultados, é necessário acompanhar e promover ações junto a municípios que apresentem níveis de proficiência abaixo da média, a fim de diminuir a dispersão observada nos últimos anos. 


\section{A ESTRATÉGIA DE IDENTIFICAÇÃO E OS RESULTADOS DA AVALIAÇÃO DE IMPACTO}

Para aferir o efeito da lei cearense, dois estudos devem ser considerados como base, Petterini e Irffi (2013) e Brandão (2014), por utilizarem dados municipais. Além disso, emprega-se ainda estratégia semelhante à de Carneiro e Irffi (2018a) por levar em conta múltiplos grupos de controle como forma de comparação. Ressaltando que, por usar dados municipais, não se pode comparar os resultados desta análise aos de Carneiro e Irffi (2018a).

Como estratégia de estimação, utiliza-se o modelo de diferença-em-diferenças combinado com pareamento por escore de propensão, para o período de 2007 a 2017, respectivamente, antes e após a Lei $\mathrm{n}^{\mathrm{O}}$ 14.023/2007. Em relação aos indicadores educacionais, são usadas as notas de proficiência em Língua Portuguesa e Matemática para o $5^{\circ}$ ano do ensino fundamental, o Ideb, a taxa de reprovação e a taxa de abandono dos anos iniciais (do $1^{\mathrm{o}}$ ao $5^{\mathrm{o}} \mathrm{do} \mathrm{EF}$ ). Quanto às covariadas, consideram-se a quantidade de alunos por turma, a taxa de professor com nível superior e o PIB per capita.

No que se refere à estratégia de identificação, primeiramente, apoia-se no estudo de Petterini e Irffi (2013) para comparar os resultados educacionais dos municípios cearenses (tratados) com os dos municípios baianos (grupo de controle). Observa-se pela Tabela 12 que o efeito médio de tratamento (ATT na sigla em inglês) nas proficiências de Língua Portuguesa e Matemática no $5^{\circ}$ ano do ensino fundamental sugere uma vantagem de pelo menos 33 pontos na escala do Saeb, considerando os municípios baianos como grupo de controle. Vale ressaltar que Petterini e Irffi (2013) também encontram efeito positivo da lei cearense ao comparar os resultados dos municípios desse estado com aqueles dos municípios baianos, porém, a magnitude é pelo menos quatro vezes menor, dado que é estimada uma diferença em Língua Portuguesa entre 5,47 e 7,49 pontos, enquanto a diferença em Matemática é de 3,94 e 5,60 pontos para um intervalo de tempo pós-intervenção menor.

Em seguida, utiliza-se a estratégia de identificação similar à de Brandão (2014), ao comparar os municípios cearenses (tratados) com aqueles dos estados vizinhos (Rio Grande do Norte, Piauí e Paraíba), com exceção de Pernambuco que possui lei semelhante à do Ceará. Nota-se que os municípios cearenses apresentam, em média, 34,1 pontos a mais em Língua Portuguesa e 35,6 em Matemática do que os municípios dos estados vizinhos. A título de comparação, o efeito estimado por Brandão (2014), considerando o ano de 2011 como posterior ao tratamento, em Língua Portuguesa e Matemática é de, respectivamente, 18,8 e 17,1 pontos na Prova Brasil.

Seguindo a linha de Carneiro e Irffi (2018a), os municípios cearenses (tratados) são comparados com os demais municípios brasileiros (grupo de controle), porém, aqueles de estados com leis semelhantes à do Ceará não fazem parte desse grupo; ou seja, são desconsiderados os de Pernambuco, Minas Gerais e Amapá. Verifica-se que a diferença é de 30,7 pontos em Língua Portuguesa e de 33,0 em Matemática, ou seja, 
a Lei $\mathrm{n}^{0}$ 14.023/2007 afetou positivamente as proficiências nos municípios cearenses, por meio do incentivo aos prefeitos a partir da distribuição de recursos da quota-parte do ICMS com base em resultados educacionais.

Além dessas estratégias, comparam-se os resultados educacionais dos municípios cearenses aos dos municípios de Sergipe e de Alagoas, que tiveram leis aprovadas posteriormente ao ano de 2017. Ressalta-se que esse é o último ano da análise, então, os municípios desses estados podem ser considerados como controle, por não terem lei similar em vigor durante o período de 2007 a 2017; em outros termos, não são afetados pelo tratamento (lei de incentivo aos prefeitos por meio da distribuição de recursos da quota-parte do "ICMS-educacional”). Em relação aos resultados, verifica-se que os municípios cearenses apresentam diferenças significativas, quando comparados com os sergipanos e alagoanos, tanto em Língua Portuguesa quanto em Matemática.

Para analisar a eficiência da Lei $\mathrm{n}^{0}$ 14.023/2007, adota-se, como estratégia de identificação, a comparação entre os municípios cearenses (tratados) e os: 1) amapaenses; 2) mineiros; e 3) pernambucanos. Nesses casos, essa comparação não capta o efeito de ter ou não lei de incentivo por meio do "ICMS-educacional", uma vez que os municípios estão em estados com leis que distribuem quota-parte de ICMS com base em indicadores educacionais. Sendo assim, essa comparação visa captar qual lei é mais eficiente em promover melhores resultados na educação.

Analisando os resultados, verifica-se que a lei cearense é mais eficiente do que a mineira, haja vista que o efeito do modelo de diferença-em-diferenças é positivo e significativo para o Ceará tanto em Língua Portuguesa quanto em Matemática. O mesmo pode ser inferido a partir da comparação com os municípios pernambucanos e amapaenses, todavia, neste último caso, em função da quantidade de observações (número de municípios) ser muito pequena, os resultados devem ser analisados com parcimônia.

No que se refere à magnitude dos resultados, observa-se que o impacto é maior na comparação com os municípios pernambucanos (média de 28 pontos tanto em Língua Portuguesa quanto em Matemática) do que com os mineiros. Mesmo assim, a diferença de 15,9 e 20,9 pontos em Língua Portuguesa e Matemática, respectivamente, na escala do Saeb é significativa. Essa diferença pode ser associada ao tamanho do prêmio oferecido pelo governo cearense, $18 \%$ da quota-parte é distribuída conforme os resultados educacionais, enquanto Minas Gerais destina 2\% (Lei $\mathrm{n}^{0} 18.030$, de 12 de janeiro de 2009) e Pernambuco, 10\% (Lei no 14.529, de 9 de dezembro de 2011); o que corrobora a derivação do modelo de Agente-Principal de Carneiro e Irffi (2018b).

De maneira geral, infere-se que a Lei $\mathrm{n}^{0}$ 14.023/2007 apresenta resultados positivos sobre as proficiências em Língua Portuguesa e Matemática dos alunos do $5^{\circ}$ ano do ensino fundamental, considerando os resultados do Saeb. Em termos de resultados, pode-se dizer que estão em linha com os observados por Petterini e Irffi (2013), Brandão (2014) e Carneiro e Irffi (2018a), porém, com base nos efeitos em 2017, verifica-se um aumento significativo referente a pontos na escala do Saeb. Portanto, conclui-se que o mecanismo de incentivo adotado pelo Ceará, ou seja, 
utilizar a quota-parte do ICMS olhando para resultados, ajuda a explicar a melhora dos municípios desse estado em exames padronizados como o Saeb. Tais resultados auxiliam na compreensão da escolha política do Acre, do Amapá, de Alagoas e de Sergipe em adotarem leis de incentivo à educação com base no rateio da quota-parte do ICMS, tendo como referência o modelo cearense. Do mesmo modo, podem explicar o aumento gradativo da vinculação do repasse de ICMS aos resultados de aprendizagem como proposto por Pernambuco.

TABELA 12

\section{EFEITO DA LEI N $14.023 / 2007$ SOBRE O DESEMPENHO DOS ALUNOS DO $5^{\circ}$ ANO} DO ENSINO FUNDAMENTAL NO SAEB

\begin{tabular}{|l|c|c|c|c|}
\multirow{2}{*}{\multicolumn{1}{|c|}{ Grupos de Controle }} & \multicolumn{2}{|c|}{ Língua Portuguesa } & \multicolumn{2}{c}{ Matemática } \\
\cline { 2 - 5 } & ATT & Erro Padrão & ATT & Erro Padrão \\
\hline Bahia & 33,883 & 3,537 & 36,390 & 4,248 \\
\hline $\begin{array}{l}\text { Piaú, Rio Grande do Norte e } \\
\text { Paraíba }\end{array}$ & 34,118 & 1,878 & 35,659 & 2,227 \\
\hline $\begin{array}{l}\text { Brasil (exceto Amapá, Ceará, } \\
\text { Minas Gerais e Pernambuco) }\end{array}$ & 30,708 & 1,733 & 33,051 & 2,100 \\
\hline Alagoas & 29,170 & 7,478 & 25,748 & 9,488 \\
\hline Sergipe & 41,632 & 3,465 & 38,916 & 4,436 \\
\hline Amapá & 54,558 & 6,902 & 40,225 & 9,317 \\
\hline Minas Gerais & 15,877 & 3,038 & 20,859 & 3,391 \\
\hline Pernambuco & 27,691 & 2,459 & 28,475 & 3,155 \\
\hline
\end{tabular}

Fonte: Elaboração própria.

Nota: Todos os resultados foram significantes com 95\% de confiança.

Além dos resultados da lei de incentivo sobre as proficiências, são analisados os efeitos em relação ao Ideb, à taxa de reprovação e à taxa de abandono dos anos iniciais. Optou-se por considerar a mesma estratégia de identificação, isto é, os mesmos grupos de comparações aos resultados dos municípios cearenses a partir de um modelo de DD.

Observa-se pela Tabela 13 que, quanto ao Ideb, os municípios cearenses apresentam resultados positivos e significativos, independentemente do grupo de controle. Verifica-se também que a menor diferença acontece em relação aos municípios mineiros, 0,691 na escala do Ideb (equivalente a 0,5 desvio padrão) ${ }^{14}$. Por outro lado, os efeitos da lei cearense comparados aos dos municípios dos estados vizinhos (Piauí, Rio Grande do Norte e Paraíba), baianos e sergipanos são superiores a 1 desvio padrão na escala do Ideb ${ }^{15}$.

Quanto ao seu efeito educacional, a lei cearense contribui de forma significativa para a redução da taxa de reprovação em relação aos municípios de estados vizinhos (isto é, Piauí, Rio Grande do Norte e Paraíba), além do grupo de comparação estabelecido

\footnotetext{
14 A Tabela A1, em apêndice, apresenta as estatísticas descritivas das variáveis de resultados.

${ }^{15} \mathrm{O}$ resultado para o Amapá não está sendo considerado pelo pequeno número de municípios no grupo de comparação.
} 
por Petterini e Irffi (2013) - municípios baianos. Todavia, quanto aos municípios alagoanos, verifica-se que o efeito estimado da lei sobre a taxa de reprovação em Alagoas tem o sentido contrário do esperado, ou seja, os municípios cearenses apresentam um aumento na taxa de reprovação quando comparados aos alagoanos. Não há diferença estatisticamente significativa em relação aos municípios de Sergipe.

No que diz respeito à efetividade da lei cearense sobre a taxa de reprovação, nota-se que não se observa diferença em relação aos municípios mineiros e pernambucanos. Ou seja, a lei cearense tem efetividade semelhante às de Minas Gerais e Pernambuco quanto à taxa de reprovação dos anos iniciais.

Analisando os efeitos sobre a taxa de abandono, verifica-se que a lei cearense não apresenta impacto quando comparada com à dos municípios baianos e sergipanos. Entretanto, no que se refere aos demais grupos de controle (Brasil - exceto Amapá, Ceará, Minas Gerais e Pernambuco -; Piauí, Rio Grande do Norte e Paraíba; e Alagoas), pode-se dizer que o efeito estimado da lei é contrário ao esperado, expressando um aumento da taxa de abandono em relação aos municípios dos grupos de comparação; uma vez que os municípios cearenses apresentam maior taxa de abandono. Em outros termos, verifica-se que a lei de incentivo no Ceará não logrou os mesmos resultados observados nos indicadores educacionais relativos a proficiências e Ideb.

TABELA 13

EFEITO DA LEI N 14.023/2007 SOBRE O IDEB, A TAXA DE REPROVAÇÃO E A TAXA DE ABANDONO NOS ANOS INICIAIS DO ENSINO FUNDAMENTAL (DO $\left.1^{\circ} \mathrm{AO} 5^{\circ} \mathrm{ANO}\right)$

\begin{tabular}{|c|c|c|c|c|c|c|}
\hline \multirow[b]{2}{*}{ Grupos de Controle } & \multicolumn{2}{|c|}{ Ideb } & \multicolumn{2}{|c|}{ Taxa de Reprovação } & \multicolumn{2}{|c|}{ Taxa de Abandono } \\
\hline & ATT & $\begin{array}{c}\text { Erro } \\
\text { Padrão }\end{array}$ & ATT & $\begin{array}{c}\text { Erro } \\
\text { Padrão }\end{array}$ & ATT & $\begin{array}{c}\text { Erro } \\
\text { Padrão }\end{array}$ \\
\hline Bahia & $1,481^{*}$ & 0,236 & $-3,476^{*}$ & 1,655 & 3,411 & 2,271 \\
\hline $\begin{array}{l}\text { Piauí, Rio Grande do } \\
\text { Norte e Paraíba }\end{array}$ & $1,378^{*}$ & 0,089 & $-1,986^{*}$ & 0,721 & $1,627^{*}$ & 0,253 \\
\hline $\begin{array}{l}\text { Brasil (ex. Amapá, } \\
\text { Ceará, Minas Gerais } \\
\text { e Pernambuco) }\end{array}$ & $1,164^{*}$ & 0,083 & $-1,425^{*}$ & 0,618 & $1,256 *$ & 0,198 \\
\hline Alagoas & $0,846^{*}$ & 0,285 & $6,517^{*}$ & 2,107 & $3,582^{*}$ & 1,000 \\
\hline Sergipe & $1,549 *$ & 0,148 & 1,071 & 1,411 & 0,373 & 0,744 \\
\hline Amapá & 2,361 * & 0,387 & - & - & $0,420 *$ & 1,187 \\
\hline Minas Gerais & $0,691^{*}$ & 0,119 & $-1,684$ & 0,980 & $-0,708^{*}$ & 0,249 \\
\hline Pernambuco & 1,021 * & 0,119 & $-0,928$ & 0,944 & $2,324^{*}$ & 0,321 \\
\hline
\end{tabular}

Fonte: Elaboração própria.

Nota: * Denota a significância ao nível de 5\%.

No que se refere à efetividade da lei, pode-se dizer que a lei cearense é mais efetiva do que a de Minas Gerais, dado que se observa uma redução da taxa de abandono nos anos iniciais no Ceará em relação aos municípios mineiros. No entanto, a lei cearense é menos efetiva do que a de Pernambuco, uma vez que a taxa de abandono dos municípios do Ceará é maior que a dos municípios pernambucanos. 


\section{CONSIDERAÇÕES FINAIS}

Este texto faz uma contextualização geral das leis vigentes sobre a distribuição de recursos da quota-parte do ICMS dos estados para os municípios e que guardam vínculo com a educação. Apresenta as semelhanças e as diferenças em relação à regra de distribuição cearense. A escolha de comparação com a lei desse estado decorre dos bons resultados apresentados pela literatura empírica e teórica.

Além dessa contextualização legal, o estudo conta com uma revisão da literatura empírica. Com base na análise desta, percebe-se que há forte evidência de que os resultados educacionais dos municípios no Ceará são afetados pela distribuição de recursos da quota-parte de ICMS, gerada a partir da Lei $\mathrm{n}^{\mathrm{0}}$ 14.023/2007.

As estimativas de impacto do "ICMS-educacional" apresentadas neste estudo corroboram as evidências dos efeitos positivos da lei do "ICMS-educacional" demonstradas em investigações anteriores. Além disso, este texto destaca o diferencial de impacto da lei da quota-parte cearense em relação às demais regras estaduais, considerando medidas em termos de desempenho e de fluxo educacional. A regra de distribuição do Ceará exerce um substancial impacto positivo sobre os indicadores de desempenho educacional, entretanto, os resultados apontam também efeito contrário ao esperado quanto ao abandono escolar.

\section{REFERÊNCIAS}

ACRE. Lei $n^{0}$ 3.532, de 30 de outubro de 2019. Dispõe sobre os critérios de distribuição do Imposto sobre Operações Relativas à Circulação de Mercadorias e sobre Prestações de Serviços de Transportes Interestadual e Intermunicipal e de Comunicação - ICMS, pertencente aos municípios. Rio Branco, 2019. Disponível em: <http://www.sefaz.acre.gov.br/wp-content/uploads/Lei-n-3.532-de-30-de-outubro-de2019-IPM-ICMS.pdf>. Acesso em: 5 fev. 2021.

ALAGOAS. Lei $n^{\circ}$ 8.234, de 10 de janeiro de 2020. Altera a lei estadual $n^{0} 5.981$, de 19 de dezembro de 1997, que consolida os critérios de apuração, define os prazos de entrega das parcelas do produto da arrecadação dos impostos que menciona e das transferências, asseguradas aos municípios alagoanos, e dá outras providências. Maceió, 2020. Disponível em: <https://sapl.al.al.leg.br/media/sapl/public/ normajuridica/2020/1779/lei_no_8.234_de_10_de_janeiro_de_2020_1.pdf $>$. Acesso em: 5 fev. 2021.

AMAPÁ. Lei nº 0119, de 22 de novembro de 1993. Estabelece critérios e prazos para distribuição nos municípios das parcelas de impostos estaduais, conforme 
disposições contidas na Constituição Estadual. Diário Oficial do Estado do Amapá, Macapá, 23 nov. 1993.

AMAPÁ. Lei nº 0322, de 23 de dezembro de 1996. Dispõe sobre distribuição da parcela da receita do produto da arrecadação dos impostos estaduais conforme disposições contidas no Artigo 158 da Constituição Federal e Lei Complementar Federal $\mathrm{n}^{0}$ 63/90, e dá outras providências. Alterada pela Lei $\mathrm{n}^{0} 2.175$, de 11 de maio de 2017. Diário Oficial do Estado do Amapá, Macapá, 23 dez. 1996.

AMAPÁ. Lei Complementar no 0120, de 2 de dezembro de 2019. Dispõe sobre a distribuição das parcelas do ICMS e outros tributos arrecadados pelo Estado e por este recebidas, pertencentes aos Municípios, de acordo com a Lei Complementar $n^{\circ}$ 63/90, e dá outras providências. Diário Oficial do Estado do Amapá, Macapá, 2 dez. 2019.

BRANDÃO, J. B. O rateio de ICMS por desempenho de municípios no Ceará e seu impacto em indicadores do sistema de avaliação da educação. 2014. 87 f. Dissertação (Mestrado em Administração) - Escola Brasileira de Administração Pública e de Empresas, Fundação Getúlio Vargas, Rio de Janeiro, 2014.

BRASIL. Lei $\mathrm{n}^{0}$ 9.394, de 20 de dezembro de 1996. Estabelece as diretrizes e bases da educação nacional. Diário Oficial da União, Brasília, DF, 23 dez. 1996. Seção 1, p. 27833.

BRASIL. Constituição (1988). Constituição da República Federativa do Brasil. Brasília, DF, 1988.

BRASIL. Instituto Nacional de Estudos e Pesquisas Educacionais Anísio Teixeira (Inep). Índice de Desenvolvimento da Educação Básica (Ideb). Brasília, DF, [s. d.]. Disponível em: <http://ideb.inep.gov.br/.> Acesso em: 8 fev. 2021.

BRASIL. Instituto Nacional de Estudos e Pesquisas Educacionais Anísio Teixeira (Inep). Microdados: Censo Escolar. Brasília, DF, [s. d.]. Disponível em: <http://portal. inep.gov.br/microdados >. Acesso em: 8 fev. 2021.

BRASIL. Instituto Nacional de Estudos e Pesquisas Educacionais Anísio Teixeira (Inep). Sinopses Estatísticas da Educação Básica. Brasília, DF, [s. d.]. Disponível em: $<$ http://portal.inep.gov.br/web/guest/sinopses-estatisticas-da-educacao-basica> . Acesso em: 8 fev. 2021.

BRUNOZI JÚNIOR, A. C. et al. Efeitos da Lei Robin Hood sobre os critérios de transferência do ICMS e avaliação de seu impacto nos municípios mineiros. RIC: Revista de Informação Contábil, Recife, v. 2, n. 4, p. 82-101, 2008. 
BRUNOZI JÚNIOR, A. C. et al. Efeitos das transferências intergovernamentais e arrecadação tributária sobre os indicadores sociais da saúde e educação em Minas Gerais. RIC: Revista de Informação Contábil, Recife, v. 5, n. 2, p. 99-121, 2011.

CARNEIRO, D. R. F. Avaliação de políticas de incentivo à educação básica no Ceará: lições para o Brasil. 2018. 124 f. Tese (Doutorado em Economia) - Departamento de Economia Aplicada, Universidade Federal do Ceará, Fortaleza, 2018.

CARNEIRO, D. R. F.; IRFFI, G. Políticas de incentivo à educação no Ceará: análise comparativa das leis de distribuição da cota-parte do ICMS. In: SACHSIDA, A. Políticas públicas: avaliando mais de meio trilhão de reais em gastos públicos. Brasília, DF: Ipea, 2018a. p. 317-349.

CARNEIRO, D. R. F.; IRFFI, G. Problema do risco moral na educação básica: um modelo agente-principal para a distribuição de recursos da cota parte do ICMS. Fortaleza: CAEN/UFC, 2018b.

CEARÁ. Lei $n^{\circ}$ 12.172, de 24 de setembro de 1993. Dá nova redação ao artigo $1^{\circ}$ da lei $\mathrm{n}^{\mathrm{o}} 11.832 / 91$, que dispõe sobre os critérios de distribuição do percentual de $25 \%$ do ICMS pertencentes aos municípios. Fortaleza, 1993. Disponível em: <https://www2. al.ce.gov.br/legislativo/legislacao5/leis93/12172.htm>. Acesso em: 5 fev. 2021.

CEARÁ. Lei no 12.612 de 7 de agosto de 1996. Define, na forma do art. 158, parágrafo único, II, da Constituição Federal, Critérios para distribuição da parcela de receita do produto de arrecadação do ICMS pertencente aos municípios. Fortaleza, 1996. Disponível em: https://www.al.ce.gov.br/legislativo/legislacao5/leis96/12612.htm. Acesso em: 20 out. 2020.

CEARÁ. Decreto no 29.306, de 5 de junho de 2008. Dispõe sobre os critérios de apuração dos índices percentuais destinados à entrega dos 25\% do ICMS pertencentes aos municípios na forma da lei $\mathrm{n}^{0} 12.612$, de 7 de agosto de 1996, alterada pela lei $\mathrm{n}^{0} 14.023$, de 17 de dezembro de 2007, e dá outras providências. Diário Oficial do Estado do Ceará, Fortaleza, 6 jun. 2008.

CEARÁ. Lei $n^{\circ}$ 14.023, de 17 de dezembro de 2007. Modifica dispositivos da Lei $\mathrm{n}^{0} 12.612$, de 7 de agosto de 1996, que define critérios para distribuição da parcela de receita do produto e arrecadação do Imposto sobre Operações relativas à circulação de mercadorias e sobre prestação de serviços de transporte interestadual e intermunicipal e de comunicação - ICMS, pertencente aos municípios e dá outras providências. Fortaleza, 2007. Disponível em: <https://www.al.ce.gov.br/legislativo/ legislacao5/leis2007/14023.htm>. Acesso em: 20 out. 2020.

CEARÁ. Lei $n^{\circ}$ 15.922, de 15 de dezembro de 2015. Altera a redação do inciso II do art. . $^{\circ}$ da Lei n. ${ }^{\circ}$ 12.612, de 7 de agosto de 1996. Fortaleza, 2015. Disponível em: 
<https://www2.al.ce.gov.br/legislativo/legislacao5/leis2015/15922>. Acesso em: 20 de out. 2020.

CEARÁ. Decreto ${ }^{\circ}$ 30.796, de 29 de dezembro de 2011. Altera dispositivos do Decreto $\mathrm{n}^{0}$ 29.881, de 31 de agosto de 2009, e dá outras providências. Fortaleza, 2009. Disponível em: <https://www.ipece.ce.gov.br/wp-content/uploads/ sites/45/2016/06/Decreto30796_29_12_2011.pdf>. Acesso em: 20 out. 2020.

CEARÁ. Lei $n^{\circ}$ 17.130, de 12 de dezembro de 2019. Altera redação do art. 2. ${ }^{\circ}$ da Lei n. ${ }^{\circ}$ 15.922, de 15 de dezembro de 2015. Fortaleza, 2019. Disponível em: <https://www2. al.ce.gov.br/legislativo/legislacao5/leis2019/17130> . Acesso em: 20 de out. 2020.

CEARÁ. Secretaria da Educação (Seduc). Seja bem-vindo ao Spaece! [Fortaleza], 2018. Disponível em: <http://www.spaece.caedufjf.net/>. Acesso em: 8 fev. 2021.

CEARÁ. Secretaria da Educação (Seduc). Spaece Alfa. [Fortaleza], [s. d.]. Disponível em: <https://webftp2.seduc.ce.gov.br/index.php/s/stHCfxXe9K88ZiR?path=\%2FSPA ECE\%2FSPAECE\%20ALFA>. Acesso em: 8 fev. 2021.

CEARÁ. Secretaria da Educação (Seduc). Spaece: Sistema Permanente de Avaliação da Educação Básica. [Fortaleza], [s. d.]. Disponível em: < https://www.seduc.ce.gov. br/spaece/>. Acesso em: 8 fev. 2021.

COSTA, L. O.; PAIVA, W. L. Memória de cálculo dos coeficientes de distribuição do ICMS municipal 2010. Fortaleza: Instituto de Pesquisa e Estratégia Econômica do Ceará, 2009. Nota Técnica $\mathrm{n}^{\circ} 39$.

FRANCA, E. M. Repasse da cota-parte do ICMS aos municípios cearenses: avaliação das mudanças ocorridas no período de 2009 a 2011. 2014. 77 f. Dissertação (Mestrado Profissional em Economia do Setor Público) - Universidade Federal do Ceará, Fortaleza, 2014.

GARCIA, F. G.; SIMONASSI, A. G.; COSTA, R. F. R. A Lei 14.023/07 e os investimentos em educação fundamental e saúde nos municípios cearenses: uma análise no período 2006-2010. Revista Economia e Desenvolvimento, João Pessoa, v. 14, n. 1, p. 3-24, 2015.

GLEWWE, P.; KREMER, M. Schools, teachers, and education outcomes in developing countries. In: HANUSHEK, E.; WELCH, F. Handbook of the Economics of Education. [S. 1.]: North Holland Publishing, 2006. p. 945-1017.

HOLANDA, M. C. et al. Proposta de mudança no rateio da cota parte do ICMS entre os municípios cearenses. Fortaleza: Instituto de Pesquisa e Estratégia Econômica do Ceará, 2007. 
HOLANDA, M. C.; BARBOSA, M. P.; COSTA, L. O. Metodologia de cálculo da nova Lei do ICMS municipal. Fortaleza: Instituto de Pesquisa e Estratégia Econômica do Ceará, 2008. Nota Técnica no 33.

LOPES, S. M. F. O ICMS socioambiental como instrumento de política pública de desenvolvimento sustentável no Estado do Ceará. 2017. 50 f. Dissertação (Mestrado Profissional em Economia do Setor Público) - Universidade Federal do Ceará, Fortaleza, 2017.

MANKIW, N. G. Introdução à Economia: princípios de micro e macroeconomia. Rio de Janeiro: Elsevier, 2001.

MARANDUBA JÚNIOR, N. G.; ALMEIDA, E. S. Análise de convergência espacial dos repasses da Lei Robin Hood. Economia e Sociedade, Campinas, v. 18, n. 3, p. 583-601, 2009.

MINAS GERAIS. Lei $n^{\circ}$ 13.803, de 27 de dezembro de 2000. Dispõe sobre a distribuição da parcela da receita do produto da arrecadação do ICMS pertencente aos municípios. Belo Horizonte, 2000. Disponível em: < http://www.fazenda.mg.gov. br/governo/assuntos_municipais/legislacao/leiestadual13803_00.html >. Acesso em: 5 fev. 2021.

MINAS GERAIS. Lei no 18.030, de 12 de janeiro de 2009. Dispõe sobre a distribuição da parcela da receita do produto da Arrecadação do ICMS pertencente aos municípios. Belo Horizonte, 2009. Disponível em: < http:/www.fazenda.mg.gov.br/ empresas/legislacao_tributaria/leis/2009/118030_2009.html>. Acesso em: 5 fev. 2021.

NOGUEIRA, C. A. G. Efeitos distributivos das políticas públicas: o caso da nova metodologia de cálculo da cota parte do ICMS do Ceará. Revista FSA, Teresina, v. 9, n. 1, p. 55-69, 2012.

PAIVA, W. L. Memória de cálculo dos coeficientes e distribuição do ICMS municipal 2017. Fortaleza: Instituto de Pesquisa e Estratégia Econômica do Ceará, 2017. Nota Técnica $n^{\circ} 63$.

PERNAMBUCO. Lei $\mathrm{n}^{0}$ 10.489, de 2 de outubro de 1990. Dispõe sobre a distribuição, entre os municípios, da parcela do ICMS que lhes é destinada. Diário Oficial do Estado do Pernambuco, Recife, 3 out. 1990.

PERNAMBUCO. Lei n ${ }^{0}$ 11.899, de 21 de dezembro de 2000. Redefine os critérios de distribuição da parte do ICMS que cabe aos municípios, de que trata o artigo $2^{\circ}$, da Lei $\mathrm{n}^{\mathrm{o}} 10.489$, de 2 de outubro de 1990, considerando aspectos socioambientais, e dá outras providências. Diário Oficial do Estado do Pernambuco, Recife, 22 dez. 2000. 
PERNAMBUCO. Lei n ${ }^{\circ}$ 12.206, de 20 de maio de 2002. Ajusta os critérios de distribuição de parte do ICMS que cabe aos Municípios, nos termos do art. $2^{\circ}$, da Lei $\mathrm{n}^{\circ} 10.489$, de 2 de outubro de 1990, com a redação da Lei no 11.899, de 21 de dezembro de 2000, relativamente aos aspectos socioambientais. Diário Oficial do Estado do Pernambuco, Recife, 21 maio 2002.

PERNAMBUCO. Lei $\mathrm{n}^{\circ}$ 12.432, de 29 de setembro de 2003. Ajusta os critérios de distribuição de parte do ICMS que cabe aos Municípios, nos termos do art. $2^{\circ}$, da Lei $\mathrm{n}^{\circ}$ 10.489, de 2 de outubro de 1990, com a redação da Lei n ${ }^{0}$ 11.899, de 21 de dezembro de 2000, e da Lei n $\mathrm{n}^{\mathrm{1}}$ 12.206, de 20 de maio de 2002. Diário Oficial do Estado do Pernambuco, Recife, 30 set. 2003.

PERNAMBUCO. Lei $\mathrm{n}^{0}$ 13.368, de 14 de dezembro de 2007. Ajusta critérios de distribuição de parte do ICMS que cabe aos Municípios, nos termos da Lei n ${ }^{\circ} 10.489$, de 02 de outubro de 1990, e alterações. Diário Oficial do Estado do Pernambuco, Recife, 15 dez. 2007.

PERNAMBUCO. Lei $\mathrm{n}^{\mathrm{o}}$ 14.529, de 9 de dezembro de 2011. Modifica a Lei $\mathrm{n}^{\mathrm{o}}$ 10.489, de 2 de outubro de 1990, relativamente a redefinições de critérios de distribuição de parte do ICMS que cabe aos municípios. Diário Oficial do Estado de Pernambuco, Recife, 10 dez. 2011.

PERNAMBUCO. Lei $\mathrm{n}^{\mathrm{o}}$ 16.616, de 15 de julho de 2019. Modifica a Lei $\mathrm{n}^{0} 10.489$, de 2 de outubro de 1990, relativamente a redefinições de critérios de distribuição de parte do ICMS que cabe aos municípios. Diário Oficial do Estado de Pernambuco, Recife, 16 jul. 2019.

PETTERINI, F. C.; IRFFI, G. D. Evaluating the impact of a change in the ICMS tax law in the state of Ceará in municipal education and health indicators. Economia, [S. l.], v. 14, n. 3-4, p. 171-184, 2013.

SERGIPE. Lei $\mathrm{n}^{\circ}$ 8.628, de 5 de dezembro de 2019. Cria o ICMS-Social e estabelece, na forma do inciso IV do art. 158 e do inciso II do parágrafo único do mesmo dispositivo da Constituição Federal, critérios para a distribuição da parcela da receita do produto da arrecadação do Imposto sobre Operações Relativas à Circulação de Mercadorias e sobre Prestações de Serviços de Transporte Interestadual e Intermunicipal e de Comunicação - ICMS, pertencente aos Municípios, e dá providências correlatas. Diário Oficial do Estado de Sergipe, Aracaju, 6 dez. 2019.

SIMÕES, A. A.; ARAÚJO, E. A. O ICMS e sua potencialidade como instrumento de política educacional. In: MORAES, G. H.; ALBUQUERQUE, A. E. M. Cadernos de estudos e pesquisas em políticas educacionais: pesquisa em educação e 
transformação. Brasília, DF: Instituto Nacional de Estudos e Pesquisas Educacionais Anísio Teixeira, 2019. v. 3.

SOBRAL, E. F. M.; SILVA JUNIOR, L. H. O ICMS socioambiental de Pernambuco: uma avaliação dos componentes socioeconômicos da política a partir do processo de Markov. Planejamento e Políticas Públicas, Brasília, DF, n. 42, p. 189-217, jan./jun. 2014.

WANDERLEY, C. B. Transferências federativas e potência dos contratos: avaliação da Lei Robin Hood. Rio de Janeiro: EPGE/FGV, 2005. 


\section{APÊNDICE}

\section{QUADRO A1}

\section{LEIS QUE MUDARAM O REGIME DE REPARTIÇÃO DA QUOTA-PARTE DO ICMS NO ESTADO DO CEARÁ - 2001-2019}

\begin{tabular}{|c|c|}
\hline Lei & Link \\
\hline $\begin{array}{l}\text { Lei } \mathrm{n}^{0} 12.172 \text {, de } 24 \\
\text { de setembro de } 1993\end{array}$ & https://www2.al.ce.gov.br/legislativo/legislacao5/leis93/12172.htm \\
\hline $\begin{array}{l}\text { Lei } \mathrm{n}^{0} 12.612 \text {, de } 7 \\
\text { de agosto de } 1996\end{array}$ & https://www2.al.ce.gov.br/legislativo/legislacao5/leis96/12612.htm \\
\hline $\begin{array}{l}\text { Lei } \mathrm{n}^{0} 14.023 \text {, de } 17 \\
\text { de dezembro de } 2007\end{array}$ & https://www2.al.ce.gov.br/legislativo/legislacao5/leis2007/14023.htm \\
\hline $\begin{array}{l}\text { Lei } n^{0} 15.922 \text {, de } 15 \\
\text { de dezembro de } 2015\end{array}$ & https://www2.al.ce.gov.br/legislativo/legislacao5/leis2015/15922.htm \\
\hline $\begin{array}{l}\text { Lei } n^{0} 17.130 \text {, de } 12 \\
\text { de dezembro de } 2019\end{array}$ & https://www2.al.ce.gov.br/legislativo/legislacao5/leis2019/17130 \\
\hline
\end{tabular}

Fonte: Elaboração própria.

TABELA A1

ESTATÍSTICAS DESCRITIVAS DAS VARIÁVEIS DE RESULTADOS EDUCACIONAIS DOS MUNICÍPIOS BRASILEIROS A PARTIR DOS DADOS DA PROVA BRASIL E DO CENSO DA EDUCAÇÃO BÁSICA

\begin{tabular}{|l|r|r|r|r|c}
\multicolumn{1}{|c|}{ Variável } & Média & $\begin{array}{c}\text { Desvio } \\
\text { Padrão }\end{array}$ & Mínimo & Máximo & Observações \\
\hline Língua Portuguesa & 206,81 & 34,66 & 119,03 & 311,81 & 17.193 \\
\hline Matemática & 218,02 & 31,30 & 132,73 & 340,33 & 17.193 \\
\hline Ideb & 4,6 & 1,2 & 1,6 & 9,1 & 16.819 \\
\hline Taxa de Reprovação & 9,66 & 7,38 & 0 & 52,3 & 17.185 \\
\hline Taxa de Abandono & 2,14 & 3,25 & 0 & 30,1 & 17.185 \\
\hline
\end{tabular}

Fonte: Elaboração própria.

Nota: Proficiência em Língua Portuguesa e Matemática do $5^{\circ}$ ano do ensino fundamental; Ideb das séries iniciais do ensino fundamental; taxa de reprovação e taxa de abandono para os anos iniciais do ensino fundamental (do $1^{\circ}$ ao $5^{\circ}$ ano). 
